\title{
Hacia una teoría axiológica de la sociedad: hipótesis para un esbozo
}

\author{
Francisco Parra Luna \\ Universidad Complutense de Madrid \\ parraluna@ucm.cps.es
}

\section{Resumen}

Desde las sociedades globales a las organizaciones minúsculas, los sistemas sociales se componen de seres humanos. El reconocimiento de este hecho tienen implicaciones epistemológicas importantes, puesto que, al contrario de algunas formulaciones teóricas (por ejemplo, la de la «sociedad sin hombres» de N. Luhmann), que sólo contempla a los seres humanos como elementos cruciales de cualquier tipo de sociedad, es posible percibir sus necesidades $y$, en consecuencia, los valores que supuestamente les satifacen. El binomio «necesidad/valor» deviene la primera materia esencial del análisis sociológico. Tanto necesidades como factor de motivación, como valores como factor de satisfacción, pueden ser operacionalizados y cuantificados para detectar los resultados principales de organizaciones sociales complejas, su desviación de estandares predeterminados y su adaptación al ambiente.

Palabras clave: necesidad, valor, eficiencia, perfil axiológico, cambio.

\section{Abstract. An axiological theory: outline hypothesis}

Social systems, from global societies to small organizations, are made up of human beings. Acknowledgement of this fact has important epistemological implications, since, contrary to some theoretical formulations (e.g., the «society without men» of N. Luhmann), only by regarding human beings as the crucial element of any type of society it is possible to perceive their needs and therefore the values supposedly intended to satisfy them. The «need / value» binomial thereby becomes the essential prime material of sociological analysis. Both NEEDS as a factor of motivation and VALUES as a factor of satisfaction can be operationalized and quantified to depict the principal achievements of complex social organizations, their deviation from predetermined standards and the extent to which they ultimately adapt to the environment. Standardized and therefore comparable axiological profiles comprise a tool that can be generally applied to establish a preliminary measure of the degree of overall organizational efficiency. The concept of organization is taken here in its broader sense and is applicable to any type of society organized so as to achieve certain goals.

Key words: need, value, efficiency, axiological profile, change.

* Publicado previamente en inglés en Systems Research and Behavioral Sciences, 18, 479-503 (2001). 


\section{Sumario}

Introducción 15. Análisis desviacional

1. Rehumanización 16. Cambio social

2. Carenciación 17. Progreso/regresión social

3. Sinergia social 18. Comportamiento ético

4. Relevancia 19. Teoría crítica

5. Axiologización 20. Diagnóstico organizacional

6. Transformación 21. Análisis explicativos

7. Finalidad 22. Análisis cibernético

8. Universalización 23. Diseño de sistemas de información

9. Cuantificación 24. Procesos de decisión

10. Porcentualización 25. Optimización

11. Perfilación 26. Intervención

12. Subjetivación 27. Evaluación de la intervención

13. Sociologización Conclusión

14. Eficiencia organizacional Bibliografía

\section{Introducción}

Las teorías sobre la sociedad son múltiples, y puede decirse que casi todas ellas han jugado papeles relevantes en la investigación social. Buena parte del conocimiento acumulado sobre el funcionamiento de las sociedades, se debe a esos esquemas de ideas (no siempre organizados en sistemas de proposiciones) más o menos empíricamente verificados. Las hipótesis o principios que seguirán van a intentar presentar una concepción axiológica de la sociedad que, al estar previamente inspiradas en una teoría crítica de la misma (a su vez como teoría del objeto y como método de conocimiento), mostrarán (o deberían mostrar) una irrenunciable vocación hacia la integración con el resto de las teorías conocidas, a sabiendas de que todas ellas encierran algún grado de verdad. Cualquier teoría, enfoque o método, por novedoso o revolucionario que parezca, no puede aspirar sino a ser complementario de las teorías existentes (Flood y Jackson, 1991).

En estos momentos dos nuevos ejes parecen entrecruzar el campo de las teorías sociológicas, superponiéndose además a los viejos enfrentamientos consensualismo/conflictivismo, empirismo/teoría crítica o gran teoría/interaccionalismo simbólico, por citar sólo algunos. Los dos ejes añadidos estarían representados por las controversias realismo/constructivismo y sistemismo/posmodernismo. El realismo recargaría las tintas sobre la objetividad del mundo real con independencia de la percepción del observador, argumentando que la observación queda adecuada e implícitamente validada por la ortodoxa utilización del método científico (acuerdo intersubjetivo entre expertos); mientras 
que el constructivismo tiende a presentar la «realidad» como una mera construccion subjetiva del observador, aduciendo en consecuencia a la insalvable necesidad de "observar la observación» y de reivindicar la práctica de lo que llaman "pensamiento de segundo orden" o "second-order cybernetics». En el otro eje, las sociedades son para los sistémicos conjuntos de elementos interrelacionados en búsqueda de determinados fines, donde no es posible comprender una parte sin comprender la totalidad, y obligando por ello a la percepción epistemológica del «bosque» antes que a la del «árbol»; mientras que los posmodernos tienden al analisis aceradamente crítico de los elementos fragmentados de la totalidad y donde se acentuan por contra las irregularidares, lo singular, lo inesperado... y, en definitiva, la complejidad inexplicable y el caos. Pero lejos de resultar infecundos o no provechosos estos enfoques teóricos, aparentemente contradictorios, puede decirse que contribuyen a iluminar y transparentar las estructuras sociales, mucho más que si no existieran tales perspectivas y controversias. Baste recordar las aplicaciones conversacionales de la dialéctica hegeliana (si a una tesis se le antepone una antítesis, surge una síntesis que las supera a ambas) o el perspectivismo de Ortega y Gasset en su conocida contemplación de la sierra de Guadarrama. Mi posición personal se parece mucho a la de Best y Kellner (1991, p. 260), cuando resumen:

[...] while it is impossible to produce e fixed and exhausted knowledge of a constantly complex of social processes, it is possible to map the fundamental domains, structures, practices, and discurses of society, and how they are constitued and interact. Thus, in the rest of this conclusion, we shall argue for supradisciplinary social theories and a combination of micro and macroanalysis.

En cualquier caso, el punto de vista de la teoría axiológica (la que se propone acentuar la importancia de los «valores» en el análisis de lo social) va a exigir en paralelo una tendencia hacia la mejor integración y síntesis posibles de las teorías, puntos de vista, perspectivas, métodos y técnicas que se consideren más adecuadas en cada momento y contingencia.

Y a pesar, por otra parte, de la considerable diversificación de las teorías sociológicas, de la cantidad tan ingente de problemas tratados, de las numerosas especializaciones, escuelas y tendencias que hacen de la sociología un variopinto mosaico de ideas, hechos e hipótesis difíciles de ensamblar y de dotarles de un cierto sentido unitario en tanto que manifestaciones del proyecto sociohumano, sin embargo, surgiendo de esa misma complejidad acumulada, emergiendo como propiedades globales del comportamiento general de los individuos, parece posible pensar en una teoría que, tomando ya sólo la posible estructura global que surge del caos de los individualismos (Lewin, 1995) e inevitablemente abanderando los problemas más comunes y universales de la persona humana en el albor del siglo XXI, intente presentar una nueva via teórica (siempre complementaria) de mayor entendimiento, precisamente por centrarse en lo más básico de las motivaciones humanas versus lo más superficial de su comportamiento contingente. Los procesos de globalización, 
comunicación y «empequeñecimiento» del planeta, que tienden a un paralelo proceso de homogeneización y estandarización de necesidades, deseos y apetencias, contribuirían a la heurística formulación de modelos teóricos sintéticos de aplicación más generalizada. No puedo sinó estar de acuerdo con Turner (1996, p. 13) cuando dice:

In the late twentieh century it is not too difficult to predict that one possible focus for sociological theory would be the nature of citizenship and human rights [...] The debate about citizenship has been generated by a concern for the overt decline of governmental commitment to full employment and the welfare state, the changing nature of the sate itself, the growth of the global refugee problem, and the incresing ambiguity of the status of children and women in the modern state [...] It is only by engaging within the public arena with such political and social issues that sociology or general social theory can hope to survive [...] Without these political and public commitments, social theory is in danger of becoming an esoteric, elitist, and eccentric interest of marginal academics.

Es, pues, sobre esta vía más estructural que me propongo sugerir un modesto esbozo de hipótesis teóricas centradas en el relevante papel que los «valores» juegan en la vida social, sin más pretensión que la atención del lector por si algo quedara.

Las teorías sobre los «valores» no son naturalmente nuevas en sociología, donde podrían destacarse al menos tres tendencias o escuelas: la primera es la que plantearía el problema de la sociología como pretendida ciencia avalorativa o libre de valores y cuyo desarrollo va desde la conocida posición de Weber hasta el filósofo R. Rorty (1979), pasando por el crítico A. Gouldner (1971), por citar solo tres referencias conocidas. La segunda sería la que contempla a la sociedad como productora de valores y cuyo tratamiento puede verse en los trabajos que van de los «Polish Peasant...» de Thomas y Znaniencki a los recientes trabajos de B. Hall (1994); Buchanan (1999) y M. Hall (1999), pasando por Parsons y los funcionalistas, e, implícitamente, por toda la literatura crítica que va de Marx a los posmodernos (Barthes, Baudrillard, Deleuze), pasando, qué duda cabe, por las críticas profundamente axiológicas de la Escuela de Francfurt. La tercera es la que plantea los valores como "sistemas de vida» y cuyo desarrollo se puede subdividir en dos ramas: la antropológico-cultural (Kluckhohn, Strodtber, Morris, Linton...) y la que se desarrolla a través del concepto de «cultura» en la empresa y en las organizaciones (Harrison, Handy, Deal y Kennedy, Schein, Garmendia...). Basta revisar esta literatura para constatar la importancia teórica del concepto «valor» en sociología en sus múltiples versiones, pero su posible explotación teórica como «materia prima» operacional de lo social, no parece haber sido suficientemente desarrollada. La teoría axiológica que se intenta esbozar, en busca justamente de la operacionalización de esa "materia prima», caería dentro de la segunda tendencia (la producción de valores), aunque se solapará en numerosas ocasiones con las otras dos, principalmente con la concepción weberiana de la ciencia social. 
Weber, crítico e integrador a un tiempo de los enfoques historicista y utilitarista, del objetivismo y del subjetivismo, representa el esfuerzo metodológico más temprano, y aun no superado, para hacer viable un análisis científico de la sociedad. Desde la perspectiva científica, la metodología weberiana sigue representando un desafío.

Este conjunto de hipótesis pretende meramente esbozar los principios de una teoría axiológica de las organizaciones sociales, cuya finalidad última consistiría en devolver a la persona humana el protagonismo que le corresponde como sujeto a la vez histórico y epistemológico. Se postula para ello que sólo a partir de considerar a la persona humana como irrenunciable elemento central de la sociedad, es posible llegar a la teoría de las necesidades humanas y, en consecuencia, a la universalización de éstas (Declaración Universal de Derechos Humanos de la ONU), permitiendo un modelo general de evaluación intersocietal e intercultural. Y puesto que la «necesidad» y el «valor» son caras de la misma moneda (Kluckhonhn), la sociedad se axiologiza a través de un patrón referencial de valores (PRV) cuantificable y estandarizable, que debe poder expresar los grados de satisfacción deseados y conseguidos. La estrategia de integración de intereses y de implementación de políticas podría apoyarse ahora sobre una base más sólida ¿Cómo se podría, entonces, realizar el sistema de valores contingentemente adoptado por cada individuo? La experiencia histórica nos demuestra que sólo a través del "contrato social» (vida en sociedad), organizada además en «sistema transformador», es cuando se pueden obtener los más altos (o menos bajos) niveles de satisfacción. Concebida así la sociedad, ésta convierte esfuerzos y energías (medios o "entradas») en sistemas de valores (fines o «salidas»), las cuales pueden ser operacionalizadas, cuantificadas y estandarizadas para conducirnos al concepto de eficiencia organizacional o global (teoría clásica de la organización) y, sobre todo, a la elaboración analítica de perfiles axiológicos como exponentes empíricos (objetivos/subjetivos) de los diferentes sistemas de valores, con especial hincapié en el papel del observador-observado (última teoría de la organización).

Esbozo teórico que no hace en realidad sino intentar articular los frutos de trabajos anteriores. Como en algún sitio dejó escrito el llorado J. Ibáñez: «más que un gigante puede ver un enano si éste va subido sobre sus hombros». Así pues, y en términos de implicación lógica $(\rightarrow)$ el proceso de formación de la teoría se explicaría así: REHUMANIZACIÓN (Miller) $\rightarrow$ CARENCIACIÓN (Maslow) $\rightarrow$ UNIVERSALIZACIÓN (ONU) $\rightarrow$ AXIOLOGIZACIÓN (Kluckhohn) $\rightarrow$ ASOCIACIÓN (Rousseau) $\rightarrow$ SOCIOLOGIZACIÓN (Marx) $\rightarrow$ SUBJETIVACIÓN (Von Foerster) $\rightarrow$ CUANTIFICACIÓN (Lazarsfeld) $\rightarrow$ PORCENTUALIZACIÓN (UNRISD). Estos autores serían, entre otros, los gigantes particulares sobre cuyos hombros fue posible pasar a esa otra orilla pretendidamente más humanizada y operacional, cuyo resultado final se podría incluso resumir en sólo dos de los conceptos presentados: el de perfilación axiológica (hipótesis 11) y el de eficiencia organizacional (hipótesis 14).

Las hipótesis anteriores permitirían explicitar ahora los que serían los cuatro elementos angulares de toda sociedad. Las organizaciones sociales son, 


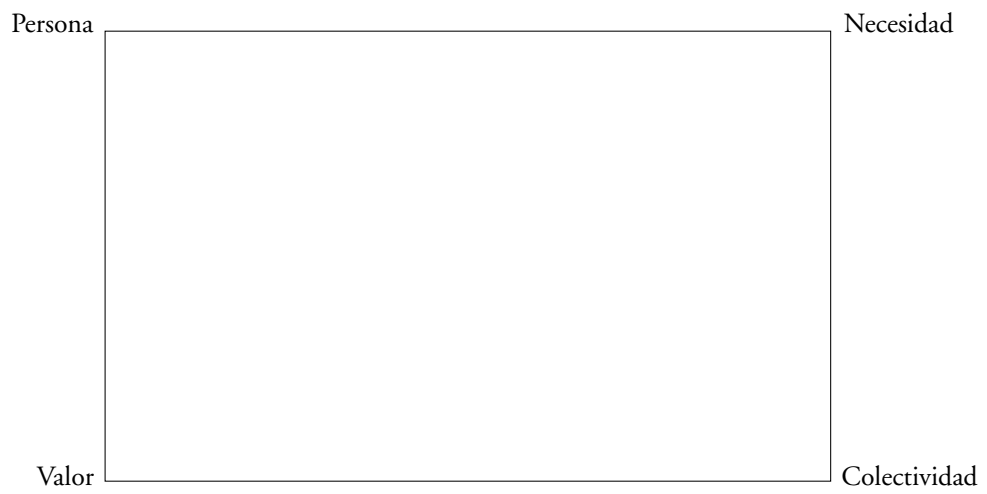

Figura 1. Elementos básicos de la organización social.

como se sabe, complejas por naturaleza, y de ahí la necesidad de separar, de entre la infinidad de sus elementos, los que en cada momento puedan considerarse como esenciales frente a otros importantes, secundarios o irrelevantes. Un elemental principio de economía nos obliga a tomar en principio sólo los esenciales, y quizás los importantes más significativos, abandonando los secundarios e irrelevantes. Operación de selección (parsimony) que no debe temerse si se es consciente de llevarla a cabo. Como viene a decir H. Simon: «Simplifiquemos; que tiempo habrá para añadir complejidades». Sobre este principio heurístico, la figura 1 señala los cuatro elementos básicos de la sociedad: la persona, la colectividad, la necesidad y el valor. Los dos primeros tendrían una naturaleza de tipo "óntico» (externos, explícitos, visibles y materiales); los dos últimos, de tipo «epistemológico» (internos, implícitos, invisibles e inmateriales).

Naturalmente, y dada la complejidad de lo social, existen infinidad de elementos que podrían considerarse también como esenciales e importantes en situaciones particulares, como por ejemplo los roles, los intercambios, las actitudes, las normas, las comunicaciones, las acciones, los signos, etc., pero ninguno de ellos alcanza la categoría de FIN último como lo son la persona (unidad de autorrealización), la colectividad (unidad de maximización), la necesidad (unidad de motivación) y el valor (unidad de satisfacción), y cuya descripción resumida es la siguiente.

\section{Unidad de autorrealización}

Las organizaciones sociales existen para autorrealizarse, lo que significa perdurar, progresar, racionalizar y reordenar sus actividades, adaptándolas óptimamente a las influencias del entorno, y en busca permanente de producir el mejor sistema de valores posible para su población. Pero si ello es así, es única 
y exclusivamente porque están compuestos por personas humanas con necesidades y apetencias, y donde la variedad y complejidad de lo social no es más que un reflejo de la variedad y complejidad de las personas en interacción. Son las propias personas las que van a intentar compaginar lo histórico (conservar lo positivo) con lo dinámico (desarrollos científico, tecnológico, institucional, etc.) para adueñarse, crítica y creativamente, de su destino individual y colectivo, y con la única misión de alcanzar las mayores cotas de bienestar posible compatibles con su autorrealización individual. Sería, por tanto, la persona humana el elemento crucial de la sociedad al tiempo su unidad más significativa de autorrealización y el fin último de su proyecto convivencial. El conocer (describir/explicar) hasta qué grado este proyecto universalizado (Declaración de Derechos Humanos de la ONU) se realiza al nivel de cada una de las personas, en cada una de las sociedades y las organizaciones, es algo que la teoría axiológica pretende facilitar.

\section{Unidad de maximación}

Si conseguir la máxima autorrealización de las personas humanas es el fin último de las organizaciones sociales, ello sólo puede lograrse a través de la armonización rutinaria de los intereses personales con los colectivos. La aventura social se convierte entonces en un proceso complejo y permanente de optimización de valores donde, de entre todos los que componen el PRV, preciso resulta destacar a los dos que van a jugar un papel crucial en el funcionamiento del sistema: el valor «libertad», para ofrecer a cada persona el máximo posible de libertades políticas, económicas, sociales y culturales, y el de «justicia distributiva», para ofrecer la máxima igualdad de oportunidades a todos. Se deduce que la única forma de que cada persona maximice la sinergia que individualmente obtiene de cada organización social es, invariablemente, a través del respeto a los intereses de la colectividad. Como menos se tarda en un trayecto urbano, es perdiendo el tiempo necesario ante los semáforos rojos, o lo que es igual, sólo sometiéndose a los superiores intereses de la colectividad resulta posible maximizar el interés individual. Cada sistema social complejo se compondría así de numerosos subsistemas, cada uno de los cuales se constituye en «unidad de maximación»

\section{Unidad de motivación}

Tanto la organización social en su conjunto como los subsistemas y las personas que lo componen se encuentran motivados sólo y exclusivamente por el deseo de satisfacer sus necesidades individuales. Es preciso, pues, identificar, inventariar y clasificar dichas necesidades antes de poder lograr su satisfacción. De acuerdo con la ley de variedad requerida (Asbhy), las unidades motivacionales del sistema serán iguales en número a las unidades de necesidad. Esto es, de cada unidad de necesidad sentida va a surgir paralelamente una unidad de motivación como potencial sinérgico del sistema, de forma que cada nueva 
unidad de necesidad puede ser contemplada como un motor adicional instalado en el sistema social (Leipziger, 1981).

\section{Unidad de satisfacción}

Se postuló que la satisfacción sólo resulta alcanzable a través del ente llamado «valor» en tanto que algo deseado, valorado y perseguido o como «algo digno de cualquier actividad» (Znaniencki). De nuevo se aplica la ley de la variedad requerida para conocer que los grados de satisfacción alcanzados se van a corresponder con los grados de «valor» realizados o, en otras palabras: a un complejo sistema de necesidades (individuales o colectivas) corresponderá idéntico complejo «sistema de valores» a satisfacer. Cualquier diferencia entre ambos puede resultar en frustración e inestabilidad para el sistema. El «valor» como unidad de satisfacción se va a tratar, en consecuencia y finalmente, como la materia prima o «unidad» operacional básica de la teoría axiológica.

Con esta finalidad, las hipótesis que siguen estarán organizadas en tres grupos. El primero comprende tres hipótesis que llamaré «ontológicas» (según su numeración: la 1, la 2 y la 3); el segundo grupo comprende diez hipótesis que llamaré «metodológicas» (de la 4 a la 13), y el tercero comprende catorce hipótesis que llamaré "prácticas» $\mathrm{u}$ "operativas», las cuales vienen a sugerir algunas de las posibilidades de aplicación de la teoría y sus aportaciones esperadas. Siguiendo este orden meramente genético-lógico, detallo en forma resumida las veintisiete hipótesis (pretendidamente fundacionales) siguientes.

\section{Rehumanización}

Frente a una teoría social que algunos han titulado de «sociedad sin hombres» (por ejemplo, Isuzquiza en referencia a la teoría de N. Luhmann), la sociedad se vuelve a contemplar aquí desde una perspectiva humanista donde la persona es la máxima protagonista, sujeto y objeto a la vez, observador y observado, consciente a un tiempo de que la sociedad existe como algo real «ahí afuera» y de que contribuye a recrearla en cada momento con su observación o "construcción" teórica (Von Foerster). La persona humana está dentro y fuera de la sociedad, lo que le va a causar problemas a la hora de objetivar el conocimiento que cree tener sobre la misma. Movido por esta ambición epistemológica, el observador va a intentar una ardua operación de "descentración epistémica» (Piaget), al tiempo que va a intentar «sociologizar» sus observaciones situándose en "las calles y plazas» de la sociedad, mezclado con el resto de los sujetos observados/observantes. Pero para exigir esta vez a la misma sociedad (a sus órganos rectores), no «acciones» o «decisiones» (Easton), ni tampoco el esquema AGIL de Parsons, ni siquiera la reivindicación más explícita de «socialización y reclutamiento político», "expresión de intereses», "agregación de intereses» y "comunicación política» (Almond), sino, por el contrario, grados suficientes de satisfacción de sus necesidades concretas (Maslow) o, en otras palabras, adecuados niveles de salud, libertades, seguridad, educación, etc. La atalaya de observación se traslada así del 
laboratorio científico o universitario a la calle, aunque lógicamente sin olvidarse de tomar los aparejos propios del oficio de observador. La unidad básica de la sociedad (unidad de decisión y de finalidad) va a volver a ser la que fue, tanto en los clásicos («el hombre es la medida de todas las cosas» de Protágoras), como en los contemporáneos (Miller, Buckley, Van Gigch, Bailey...). Un hombre que posiblemente vaya a estar a medio camino entre «el hombre es un lobo para el hombre» (Plauto, Hobbes) y el «ser hecho a imagen y semejanza de Dios» (san Agustín). Pero cualquiera que sea la posición antropológica del hombre/mujer en ese continuo, la posible teoría axiológica de la sociedad va a considerar que las unidades configuradoras de la misma no son las acciones, los roles, los intercambios, las comunicaciones o cualquier otra acción mediática que se derive de la vida en sociedad, sino las personas concretas, todos y cada uno de los individuos que la compongan en tanto que unidades de decisión autoconscientes de sus derechos y obligaciones en la sociedad y en tanto que fines últimos de la propia actividad social. No sólo no parece concebible una sociedad sin hombres («el hombre es el origen del mundo en que vive» (Maturana, 1997), sino que al eliminar al hombre caemos en la paradoja de eliminarnos a nosotros mismos como observadores, y si no hay observadores no hay observación. Por el contrario, al sujeto hay que darle su lugar (Ibáñez, 1994), pero no en el sentido aristocrático del observador en su torre de marfil, sino reconociendo el estatus de observador que se autoobserva a toda persona en sociedad, participante en un proceso a la vez constructivista (Von Foerster) y desconstructuvista (Derrida, Lyotard) de la sociedad desde sus propios intereses, convirtiéndose en absoluto protagonista de la misma. La sociedad es así para el hombre, no el hombre para la sociedad. Desde esta perspectiva clásica tipo «Man is the Measure» (Abel, 1976), se postula que el único fin de la sociedad consiste en procurar que todas y cada una de las personas que la compongan alcancen el máximo nivel de autorrealización individual; lograr, como pretendía el más joven Marx, personas completas; trabajadores creativos, participativos y desalienados; buenos padres/madres de familia; usadores de su tiempo libre en beneficio de la creatividad artística; solidarios con los que lo necesitan; etc. La "construcción social» de la persona se convierte así en un proyecto sempiterno y estimulantemente inacabado, entre otras cosas porque es posible que su quimérica perfección finalizara con la propia aventura humana o, como dice Malreaux: «Cuando el hombre está totalmente hecho no sirve sino para morir». Pero este "proyecto» y no otro es el fin supremo de la sociedad y contra este estándar — no por utópico eliminable como meta societal- es como habría de juzgarse el comportamiento global de las sociedades, a saber: por el grado en que estos ideales son alcanzados. En alcanzar el mejor conocimiento posible de este grado consistiría el cometido en ciernes de la teoría axiológica.

\section{Carenciación}

Se postula que las personas humanas son esencialmente «sentidoras de necesidades», ya sea en forma de pulsiones, sentimientos, anhelos, ambiciones, etc., 
ya se contemplen como naturales o artificiales, simples o sofisticadas, primitivas o modernas, propias o inducidas por el entorno social condicionante (Heller, 1978). Se considera que la persona humana es un «ser careciente» por naturaleza, un ser que todavía no ha satisfecho una necesidad cuando pronto va a sentir los impulsos de otra, aunque sólo sea la muy natural de descansar después de un esfuerzo o la más inducida de mantenerse en el poder político a cualquier precio. La clasificación de las necesidades de Maslow va a servir de punto de partida para la formulación de la teoría. Trabajos más recientes sobre la persona como eterno portador de necesidades (Buchanan, 1999; M. Hall, 1999; B. Hall, 1994; Maiteny, 1998) confirmarían estas segunda hipótesis. «Los únicos problemas reales son los problemas de la gente» (Sutton, 1993), y de su intensidad, número y variedad interrelacionada, va a depender el nivel de motivación de las sociedades (Leipziger, 1981) e incluso su desarrollo (McClelland). Martín López (1997) presenta, por último, el análisis de las necesidades humanas en lo que él llama "cuatro fases de la acción social», que resumo: 1) tendencia de las personas hacia la satisfacción de necesidades; 2) en qué medida se satisfacen; 3) por qué medios organizativos, y 4) cómo se distribuyen los grados de satisfacción.

El conocimiento, pues, periódico, honesto y sistemático de estas necesidades, tanto objetivas (en relación con la distancia existente entre lo que consigue la organización y su entorno más significativo para cada posible necesidad), como subjetivas (lo que cada persona señala una vez informada de las distancias anteriores), resultaría ser la ineludible obligación funcional y ética de todo responsable de la organización, única forma de humanizarla y democratizarla. Como dice Ibáñez (1990): «El paradigma de simplificación postula la dictadura (todo está prohibido menos lo que es obligatorio: sólo hay dictados e interdicciones), el paradigma de complejidad postula la democracia».

\section{Sinergia social}

Con el fin de lograr vivir con adecuados «sistemas de valores» (máximamente adaptados a las necesidades dinámicas), las personas individuales han tenido ocasión de comprobar, tanto por imperativos físico-biológicos (Morris, 1967; Wilson, 1975) como por experiencia histórica (Maiteny y Reed, 1998) que, emparejándose, agrupándose, formando tribus, creando ciudades o poniendo en marcha corporaciones complejas, van a satisfacer con mayor facilidad sus necesidades, siendo éstas inicialmente de carácter primario y, con el paso del tiempo, crecientemente más elaboradas y artificiales. El fin vocacional, pues, de toda sociedad no podría ser otro que mejor satisfacer las necesidades individuales de todas y cada una de las personas que la forman, desde las que nacen del mero instinto maternal que dio lugar a la primera sociedad conocida (madrehijo), hasta las que nacen de las modernas relaciones industriales (como la fabricación de alfileres de A. Smith). Surge entonces el concepto moderno de «sinergia social» demostrativo de la siguiente desigualdad: «Si $n$ individuos trabajando separadamente consiguen respectivamente los productos $p 1, p 2, \ldots, p n$, 
los mismos individuos trabajando cooperativamente en sociedad, obtendrán un producto total $Y$, donde $Y$ es, por regla general (salvo excepciones), mayor que la suma $p 1,+p 2,+\ldots p n$. Se postula, por tanto, que esta desigualdad es la base fundamental de la sociedad y el «cemento" que mantiene unidos a los individuos.

\section{Relevancia}

La compleja unidad del individuo humano es portadora de una inmensa variedad de necesidades, hasta el punto de que cada individuo puede presentar un «sistema de necesidades» propio diferente al del resto de los individuos de la especie, incluso de los más cercanos. Variedad que obliga a separar las necesidades humanas en dos grupos: las UNIVERSALES y las ESPECÍFICAS. Las primeras son comunes al género humano viviendo en sociedad (salud, seguridad, justicia, etc.); las segundas, propias de cada cultura, grupo, tribu o país (vestimenta, ornamentación, lengua, religión, folclore, etc.). Pero mientras éstas últimas tienden a mostrarse cuasiinfinitas en su variedad, las primeras resultan ser tan básicas, universalmente aceptadas y hasta limitadas en número (por ejemplo, la tipología de Maslow), que resultan aceptablemente identificables, definibles y operacionalizables (Hartman, 1967; Van Gigch, 1978; B. Hall, 1994). A los efectos de la teoría axiológica, resulta en una operación equivalente a separar el grano (las necesidades universales que permiten evaluar la efectividad de una sociedad en función de sus grados de satisfacción) de la paja (las necesidades culturales y específicas intratables comparativamente por su inequivalencia cultural). «Grano» $\mathrm{y}$ "paja» calificados así en función de los fines de la teoría axiológica, no de su apreciación intracultural y afectiva (Spaul, 1995). Tanto la complejidad del tema (necesidad de acotar el objeto) como los intereses de la organización, obligan a esta separación inicial que no tiene por qué mantenerse cuando se trate de problemas explicativos (hipótesis 21).

\section{Axiologización}

Se postula que la satisfacción de las necesidades humanas sólo van a poder ser satisfechas por los entes llamados «valores». Éstos son definidos como todo aquello, material o inmaterial, que se considera valioso, deseado, querido y perseguido por la mayoría de los seres humanos. El valor es «ese deseable estado final que guía la acción humana» (Smelser), o, como dice Kluckhohn: «El valor es el reverso de la medalla de la necesidad». «Los valores los puso el hombre en las cosas para conservarse; dio un sentido humano a las cosas; por eso se llama hombre, es decir: el que estima» (Nietzsche). Para Parsons los valores movilizan la iniciativa hacia fines últimos e incluso infunden significado existencial a la acción alienada (B. Turner, 1996). Sea como fuere, desde el momento en que se asume que la sociedad está dinamizada y motivada por las necesidades (Maslow, 1956), los valores se van a convertir en la «materia prima» 
por excelencia en el análisis de lo social; en la referencia obligada para conocer hasta qué punto las necesidades son satisfechas; hasta qué punto unos grupos consumen más «unidades» de valor que otros; hasta qué punto los valores perseguidos por ciertos grupos se imponen a los perseguidos por otros; cuál es la distancia entre el «sistema de valores» proyectado por una sociedad y el realmente alcanzado; qué conflictividad estructural se genera por la desigualdad en la distribución de los valores, y, en fin, qué «sistema de valores», qué tipo de vida, que Weltanschauung es capaz de ofrecer la sociedad organizada a los individuos que la componen. Nadie quizás como la llamada «literatura posmoderna» (Foucault, Barthes, Baudrillard, Lyotard, Guattari...) está sometiendo a una crítica profunda los valores que tienden a adulterar el acontecer cotidiano en las sociedades «desarrolladas». La pareja «necesidad/valor» impregnaría así, lo sepamos o no, a nivel consciente o inconsciente, toda la vida social; y sin un análisis axiológico profundo, va a resultar difícil la comprensión de su complejidad. Y si se admite, de acuerdo con Kluckhonhn, que la satisfacción de una necesidad responde a la disponibilidad de un «valor», entonces éstos últimos han de clasificarse igualmente en «universales» y «específicos». La teoría axiológica de la sociedad sólo va a tratar, pues, de los valores universales en tanto que comunes a la generalidad de las personas y susceptibles además de un tratamiento comparativo por tratarse de entidades medibles (Sorokin, 1959; Van Gigch, 1978; Deutsch, 1974; Bunge, 1989). Y cuando pase la moda del excesivo énfasis (cuando es excesivo) que lo posmoderno pone en lo singular, el acontecimiento irrepetible, lo particular frente a lo universal, el desprecio de la ciencia, la «inverificable» subjetividad y el «todo vale»... (que pasará), quedará lo que siempre fue y posiblemente será: por un lado, las «necesidades/valores» sentidos y solicitados por las personas y, por otro, su tratamiento social lo más racionalmente conjuntado (sistémico) posible; ambas preocupaciones, en búsqueda por humanas, sólo de vivir la mejor vida posible y de gozar del mejor «sistema de valores» con el mínimo esfuerzo. Así fue desde Adán y Eva (o desde Lucy) hasta nuestros días, y no parecen existir razones suficientes para pensar en la quiebra de esta constante histórica.

\section{Transformación}

Toda sociedad se organiza entonces (¿inevitablemente?) en un «sistema» (conjunto interrelacionado de personas dirigido hacia fines) de naturaleza transformadora de entradas (medios utilizados: personales, materiales y financieros) en salidas (grados de satisfacción de las necesidades de la población), que, de acuerdo con la hipótesis anterior número 4, son inevitablemente "sistemas de valores». La idea de sociedad como "ente transformador» está presente en buena parte de la literatura científico-social de Sorokin a Easton, de Von Bertalanffy a Van Gigch. Para Piaget los sistemas son invariablemente sistemas de transformación, y el propio hombre ha sido considerado como «sólo un transformador de energía» (H. Elbert), o como "una máquina a la cual ponemos lo que llamamos "alimento" y produce lo que llamamos "ideas"” 
(R. Ingersoll). Si después termina construyendo o destruyendo, regresando o progresando, es otro problema. En las hipótesis 14 a 18 se adelantarán algunas ideas dirigidas a intentar calibrar la bondad de dicha transformación.

Ahora bien, ¿va a resultar inevitable que toda organización social se convierta forzosamente en un sistema TRANSFORMADOR de «entradas» en «salidas»? ¿Va a ser la "transformación» el rasgo nuclear de su organización, la característica más estructural y constituyente de todo grupo social organizado? ¿Va a tratarse, pues, de una función de carácter ontológico y no meramente teórica o metodológica? Antes de responder a estas preguntas, es aconsejable sopesar las respuestas, porque posiblemente vayan a imprimir carácter. Posiblemente vayan a obligar al observador, y es de temer que para el resto de su vida, a dirigir su primera mirada a las «salidas» y las «entradas», a separarlas, a clasificarlas, a distinguir lo que son medios de lo que son fines, a medirlas si puede y a compararlas, a juzgar entonces la bondad de la sociedad por la relación entre ellas, al tiempo que esperando y abogando por la maximización de las salidas y la minimización de las entradas como corolario lógico de su pretendida racionalidad. Los complejos procesos explicativos de por qué se produce tal o cual relación salidas/entradas, vendrían sólo después, ya que no procedería explicar un concepto si no está previamente definido. Todo ello equivaldría a "sociologizar» la mirada, a contemplar la organización de la sociedad desde el exclusivo punto de vista del hombre de la calle, a trasladar, en definitiva, el puesto de observación del despacho a la plaza pública.

Si este tipo de «mirada» se institucionalizara en las ciencias sociales, ¿̨resultaría entonces más operativa y eficaz la gestión, la crítica y el desarrollo de las organizaciones sociales? Aunque esta "analogía transformadora» va a ser la adoptada en principio por la teoría axiológica, parece preferible dejar abiertas tales preguntas y que sea el lector quien decida la pertinencia o no del concepto sistémico y sus correspondientes implicaciones.

\section{Finalidad}

Si llamamos entonces «eficiencia transformadora» $(T)$ a la relación salidas $(Y)$ partido por entradas $(X)$, entonces puede decirse que el fin último de toda sociedad es alcanzar la elevación continua de dicho cociente $T=Y I X$, y este concepto de eficiencia, eficacia, efectividad, productividad, performance o como se le quiera llamar, dada la polisemia del mismo (Parra Luna, 1999), se convierte en el concepto estrella (implícito o explicito) del análisis social (Chen y Gough, 1995). Si a ello se añade que la expresión $T$ traduce los esfuerzos por alcanzar un desarrollo sostenible o ecológico, la sociedad no tendría entonces otra razón de ser que el mejoramiento continuo de este coeficiente, bien por elevar $Y$ manteniendo constante el consumo de $X$, bien por disminuir $X$ con el mismo nivel de $Y$, bien por lograr ambos objetivos al unísono que sería lo ideal y una muy aceptable definición de progreso social. Desde la perspectiva del segundo principio de la termodinámica (irreversibilidad de la energía), la expresión $T$ se enfrentaría así al "pecado» termodinámico que produ- 
ce toda organización social (la sociedad sería una organización «ladrona» de energía del ambiente físico envolvente y acelerador por tanto de la anunciada muerte de éste), a causa de su desarrollo negaentrópico y a veces desaforada dilapidación de recursos naturales. Este acelerado consumo de $X$ por mor de un desmedido "progreso", se está convirtiendo en una de las máximas preocupaciones de los científicos actuales, al menos desde los trabajos del Club de Roma (Forrester, 1971; Mesarovic y Pestel, 1974). La noción de desarrollo sostenible exige hoy que tan importante como el incremento de $Y$ resulta la disminución de $X$.

\section{Universalización}

El concepto de «eficiencia» representado por $T$ es en consecuencia de tal centralidad en las organizaciones sociales, que el intento de definirlo, operacionarlo, y medirlo cuantitativamente, presenta ya una literatura significativa (Fernández-Ríos y Sánchez, 1997). Pero literatura que se topa indefectiblemente con un problema aparentemente insuperable: la inexistencia de un modelo general de valores-fines o universales (como salidas de cualquier tipo de sistema social) válido para comparaciones en el tiempo y en el espacio (Kamm, 1995; Armson e Ison, 1995). El argumento básico es que no es posible estar de acuerdo con el sistema de valores que debe producir una determinada sociedad, ya que cada individuo, grupo o sociedad mantiene actitudes, necesidades, valores y proyectos de vida (Weltanschauung en suma) tan diferentes que imposibilitarían la fijación de una relación de objetivos o fines universales que pudieran servir de base a la evaluación comparativa de las organizaciones sociales.

Sin embargo, no es exactamente cierto que no exista un modelo general de necesidades universales y por tanto de valores comunes a realizar. Dicho modelo existe, no sólo por las contribuciones teóricas existentes (Maslow, 1970; Deutsch, 1974; Terleckyi, 1970; Van Gigch, 1978...) que presentan modelos prácticamente asumibles para tal función, sino, sobre todo y en particular, porque la Declaración de Derechos Humanos de la ONU de 1948 señala explícitamente que los valores de libertad, justicia, desarrollo económico, paz y seguridad, salud y otros, están promulgados como necesidades y derechos de todos los pueblos de la Tierra por los gobiernos (al día de hoy) de más de doscientos países o estados nación que actualmente configuran la ONU. El modelo de la tabla 1 reflejaría, pues, todos y cada uno de los valores presentes en la Declaración Universal, más el de "conservación de la naturaleza», ausente en dicha Declaración por comprensible carencia de la suficiente sensibilidad hacia el problema ecológico en dicha época. De forma que de ninguna manera se podría seguir argumentando que no existe un modelo universal allí donde han acabado consensuándolo los 6.000 millones de habitantes del planeta (a través de sus gobiernos), y donde, probablemente con escaso lugar para la duda, continúan y continuarán luchando por dichos derechos (Pons Ràfols, 1998; Mayor Zaragoza, 1998). 
Tabla 1. Patrón referencial de valores.

\begin{tabular}{|c|c|c|c|c|}
\hline \multicolumn{2}{|l|}{ Necesidad (N) } & \multirow[b]{2}{*}{ Función } & \multicolumn{2}{|l|}{ Valor perseguido $(\mathrm{Y})$} \\
\hline Clase & Símbolo & & Clase & Símbolo \\
\hline 1. De bienestar físico y psíquico & N1 & Sanitaria & Salud & $\mathrm{Y} 1$ \\
\hline 2. De suficiencia material & N2 & Económica & Riqueza & $\mathrm{Y} 2$ \\
\hline $\begin{array}{l}\text { 3. De protección } \\
\text { contra las eventualidades }\end{array}$ & N3 & Asegurativa & Seguridad y orden & Y3 \\
\hline $\begin{array}{l}\text { 4. De conocimiento y dominio } \\
\text { de la naturaleza }\end{array}$ & N4 & $\begin{array}{c}\text { Investigadora } \\
\text { y educativa }\end{array}$ & Conocimiento & Y4 \\
\hline $\begin{array}{l}\text { 5. De libertad de movimientos } \\
\text { y pensamiento }\end{array}$ & N5 & Liberadora & Libertad & Y5 \\
\hline 6. De equidad & N6 & Redistribuidora & Justicia & Y6 \\
\hline $\begin{array}{l}\text { 7. De poder y estima } \\
\text { de los demás }\end{array}$ & N7 & Prestigiadora & Prestigio & $\mathrm{Y} 7$ \\
\hline 8. De armonía con la naturaleza & N8 & Naturalista & $\begin{array}{l}\text { Conservación } \\
\text { de la naturaleza }\end{array}$ & Y8 \\
\hline 9. De autorrealización & N9 & Humanista & Calidad de las actividades & Y9 \\
\hline
\end{tabular}

Este modelo que llamé en trabajos anteriores PATRÓN REFERENCIAL DE VALORES (Parra Luna, 1982, 1993) intenta representar, pues, una tipología básica de las necesidades que toda persona humana, de no importa qué condición social o cultural, geográfica o política, persigue satisfacer. Dicha tabla presenta una totalidad óntico-metodológica, donde cualquier expresión de necesidad posible (y compatible con estos nueve valores) ha de tener necesariamente cabida en las definiciones operacionales concretas (indicadores) que se adopten para cada una de las nueve necesidades-valores en función del tipo de sistema y de los objetivos de la investigación. Se asume, por tanto, que lo que diferencia a los pueblos no consiste en la relación nominativa de valores de la tabla 1, sino el diferente acento relativo que por limitaciones (imperativos físico-estructurales) o por meras preferencias personales o de intereses (ideologías), se pone en la consecución de unos valores sobre otros. Dichos condicionantes físicos y preferencias son los que acaban determinando la considerable variedad de sistemas de valores (estructuras ideológicas) que presentan las diferentes sociedades en el tiempo y en el espacio. La compleja variedad ideológica o de «sistemas de vida» viene dada, pues, sólo y exclusivamente, por el acento relativo puesto en la realización de los valores, no en la mera relación de valores que se postula como común a todas las sociedades actuales (ONU, 1948), lo que hace posible su estructuración de un modelo general.

\section{Cuantificación}

En la mayoría de los casos no tiene porqué resultar imposible la cuantificación tanto de las entradas como de las salidas, dadas las tres tendencias que 
se observan en las sociedades avanzadas actuales, a saber: 1) la creciente numerización de los hechos acaecidos en las sociedades complejas, que están originando una producción masiva de cifras estadísticas, así como la creación de bancos de datos por multitud de organismos nacionales e internacionales, corporativos y empresariales; 2) el progreso de las metodologías de tratamiento cualitativo y cuantitativo de los datos, y 3) la facilidad de cálculos complejos y sofisticados por el desarrollo de los hardware y software y su agresiva comercialización. Deduzco que cientos de miles de series cronológicas de datos estarían así en la base de lo que Castells (1996) llama «el espíritu del informacionalismo", al cual le atribuye la misma importancia que Weber le atribuyó al "espíritu del protestantismo» en el desarrollo de la sociedad capitalista. Redes empresariales, tecnologías, competitividad y Estado desarrollista estarían "datificados» (optimización de los procesos) como condición sine qua non para su desarrollo.

Por otra parte, y a pesar, no obstante, de las aportaciones de las metodologías llamadas «blandas» (por ejemplo, Checkland, 1981; Nadler e Hibino, 1990), se constata que sigue vigente la diferencia de estatus científico entre los lenguajes ambiguos, imprecisos, contradictorios y vagos (Lachenmeyer, 1971) y los lenguajes exactos (Kluwer y Schmidt, 1999). Se comprende que entre decir, por ejemplo, «este objeto es ligero» o decir «este objeto pesa $X$ gramos», media nada menos que la posibilidad o no de «falsar» o verificar la proposición, posibilidad que en la perspectiva científica resulta determinante. Por otra parte, «no se puede mejorar la eficacia de acción alguna si no se dispone de su medida en algún momento» (Richard, 1993). E igualmente relevantes serían las tres funciones (métrica, conceptual y crítica) que cumple la formalización matemática en sociología (Boudon, 1971). Problema diferente es que algunas tendencias posmodernas vengan a sostener que todo vale y nada vale (Best y Kellner, 1991).

El problema de la cuantificación de los conceptos sociales o «blandos» lo planteó Lazarsfeld (1965) a través de las cuatro operaciones siguientes: $a$ ) representación imaginada del concepto; $b$ ) división en dimensiones teóricas; $c$ ) subdivisión en indicadores empíricos, y $d$ ) integración de los indicadores en un índice complejo. Esta metodología exige el no despreciable esfuerzo de lograr tres acuerdos intersubjetivos entre expertos, a saber: sobre los indicadores a utilizar, sobre la validez de los datos y sobre los cálculos a realizar, todo ello como condiciones mínimas de validación/aceptación del discurso. Pero esfuerzo que desde la perspectiva científica va a presentar la enorme ventaja de «hablar sólo de lo que se puede hablar» (Wittgenstein). Someter a los conceptos de los que se habla a este tipo de operacionalización inanbigua y precisa, va a implicar sin duda encomiables grados de modestia, claridad y límites del conocimiento presentado. Si existe carencia de datos válidos, si los conceptos así operacionalizados se consideran empobrecidos en su significación semántica, si se practica un excesivo reduccionismo..., todo queda claro y a la vista; el arquitecto conceptual enseña sus planos y si a un concepto $A$ no se le quiere llamar $A$, llámesele $A$ ', o $B$ o $C$, pero háblese del mismo solo desde la honradez de los 
datos disponibles. Lo que no quiere decir que no se puedan llevar a cabo interesantes análisis sociales sin cuantificación. Lo que digo es que los valores-fines resultan cuantificables en las organizaciones complejas (Bunge, 1989) y que ello va a facilitar la crítica de lo que la organización «hace» en beneficio de las personas que la componen.

Lo que no obsta para que la información cuantificada haya de estar sometida por norma, no sólo a la crítica inicial de su validación, que se da por supuesta, sino también a la interpretación de su sentido, a su adecuada resituación histórica o hermenéutica y, en fin, a su significación demasiadas veces obscurecida por los espesos velos de los intereses humanos. Quizás pueda decirse que, si en ciencias físicas la cuantificación es condición necesaria y suficiente, en ciencias sociales la cuantificación es necesaria pero no suficiente.

\section{Porcentualización}

La metodología de Lazarsfeld implica lógicamente la utilización de indicadores empíricos expresados en unidades heterogéneas que van a imposibilitar, en dicho estado, su integración. De ahí que resulte precisa su transformación en otro tipo de unidades homogéneas directamente integrables, lo que se suele realizar mediante el conocido procedimiento estadístico de estandarizar variables. Aquí, sin embargo, se va a seguir el método de los «puntos de correspondencia» desarrollado en la década de 1970 por el UNRISD (United Nations Research Institute for Social Development). El método es simple. Por ejemplo, un responsable de ventas en una empresa prevé vender 16.000 unidades sobre un intervalo de variación entre 5.000 (mínimo o pési$\mathrm{mo})=0$, y 25.000 (máximo u óptimo) $=100$. Entonces hacemos: Si el intervalo $25.000-5.000=20.000=100$, el intervalo $16.000-5.000=11.000=$ $X$, de donde $X=55 \%$, porcentaje que vendría a representar el grado de motivación o ambición de dicho responsable al interior del intervalo 0-100 establecido. Si acabado el periodo considerado resulta que ha vendido, por ejemplo, 17.000 unidades, habría obtenido un $60 \%$ con una desviación positiva del $5 \%$. La figura 2 muestra la equivalencia entre ambas escalas: la absoluta y la porcentual.

Si esta transformación se realiza para todos y cada uno de los indicadores que operacionalicen el PRV (cada indicador conlleva sus propios intervalos, previsiones y realizaciones en números absolutos), dispondremos de porcentajes directamente comparables y sumables/promediables para expresar el nivel de comportamiento relativo de los indicadores.

Las entradas $(X)$ en el sistema transformador necesarias para el cálculo de $T=Y I X$ (costes, gastos, utilización de recursos, etc.) se calculan utilizando también los intervalos de variación, con la diferencia de conceder el estándar de «mínimo» y «óptimo» a la cantidad menor del intervalo y el de «máximo»o "pésimo» a la mayor. 


\begin{tabular}{cc|c}
\multicolumn{2}{r}{ Escala absoluta } & Escala relativa \\
Óptimo & 25.000 & 100 \\
Previsión & 16.000 & 55 \\
Pésimo & 5.000 & 0
\end{tabular}

Figura 2. Porcentualización de variables.

\section{Perfilación}

Este tipo de estandarización de las salidas permite presentar el tradicional «tablero de mandos» organizacional en forma de PERFIL AXIOLÓGICO, como señala la figura 3, donde $S=$ Salud; $R M=$ Riqueza Material; $\mathrm{Se}=$ Seguridad; $\mathrm{C}=$ Conocimiento; $\mathrm{L}=$ Libertad; JD = Justicia Distributiva; $\mathrm{P}=$ Prestigio , $\mathrm{CN}=$ Conservación de la Naturaleza, y $\mathrm{CA}=$ Calidad de las Actividades.

Cuando la perfilación axiológica se aplica a las salidas típicas de los estados nación con sus numerosos indicadores empíricos (trabajos pioneros de Bauer, Biderman, Gross y otros, 1966), los perfiles axiológicos resultantes podrían resultar útiles para focalizar el origen de las ideologías políticas en los acentos axiológicos puestos por los individuos (y trasladables a lo colectivo) con motivo de elecciones democráticas en el mejor de los casos, o bien por los intereses personales de sus élites rectoras en el peor. En cualquier caso, la figura 4 muestra los perfiles axiológicos (hipotéticos) de dos países con diferente

100

Óptimo

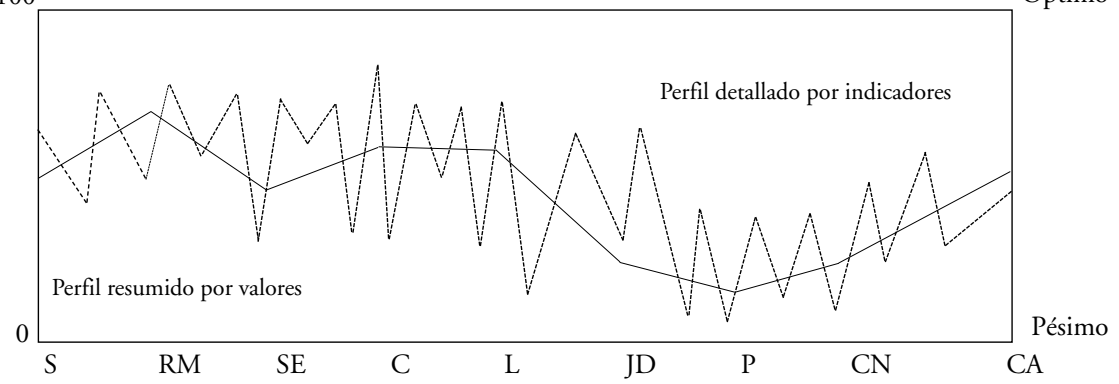

Figura 3. Perfiles axiológicos (hipotéticos). 
100 Óptimo

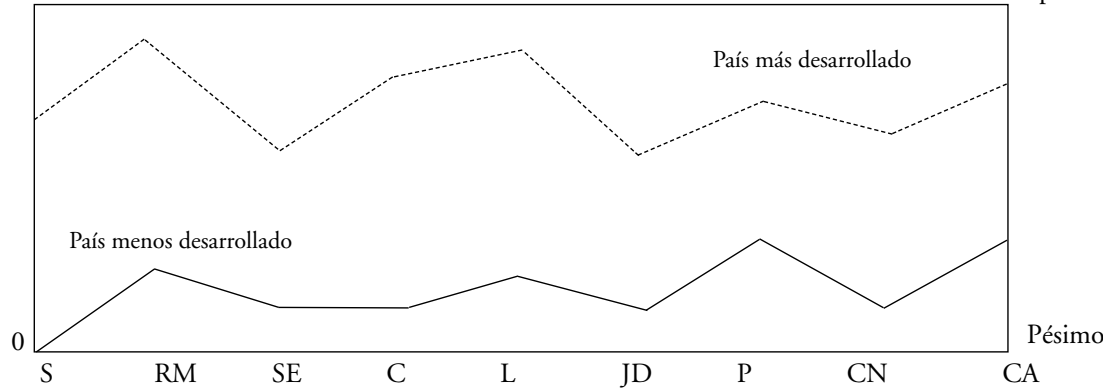

Figura 4. Perfiles hipotéticos de dos países con diferente grado de desarrollo.

grado de desarrollo, mientras que la figura 5 muestra los perfiles (teóricos o ideales) de la ideología comunista (énfasis en los valores orden y justicia distributiva y desprecio del valor libertad), y de la ideología capitalista (énfasis en el valor libertad y desprecio de los valores justicia distributiva y orden). Sólo teóricamente, por supuesto.

En este sentido, no puede argumentarse que un determinado perfil (sistema de valores) sea mejor ni peor que otro; simplemente es diferente. Lo que sí puede proporcionar una idea aproximada de la «eficacia final de las ideologías» (cuando se utilizan datos empíricos validados) es a través de comparar las áreas bajo los respectivos perfiles, ya que a una mayor extensión le corresponde una ideología, un perfil axiológico o un sistema de valores más «productivo» o que satisface las necesidades de la población con mayor amplitud. Con datos adecuados, pues, las ideologías podrían llegar a ser científicamente comparadas y sobre todo relativizadas y desposeídas de su histórica carga conflictiva.

100

Óptimo

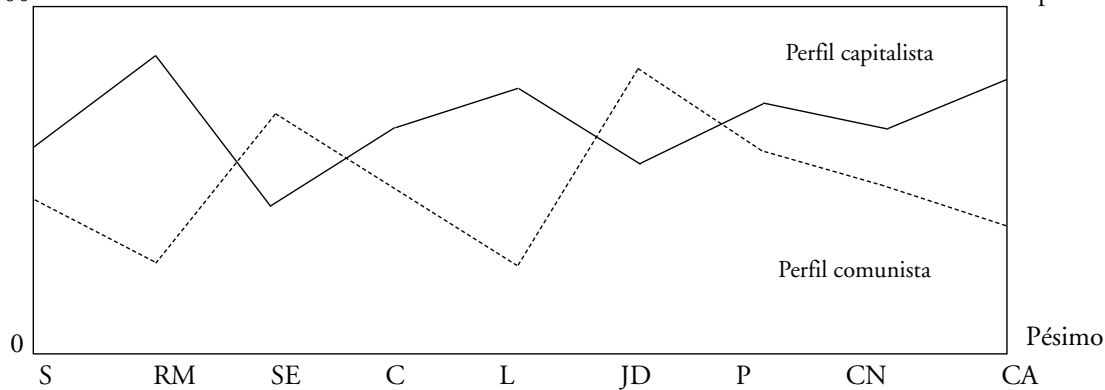

Figura 5. Perfiles axiológicos (teóricos o ideales) de las ideologías «capitalista» y «comunista». 


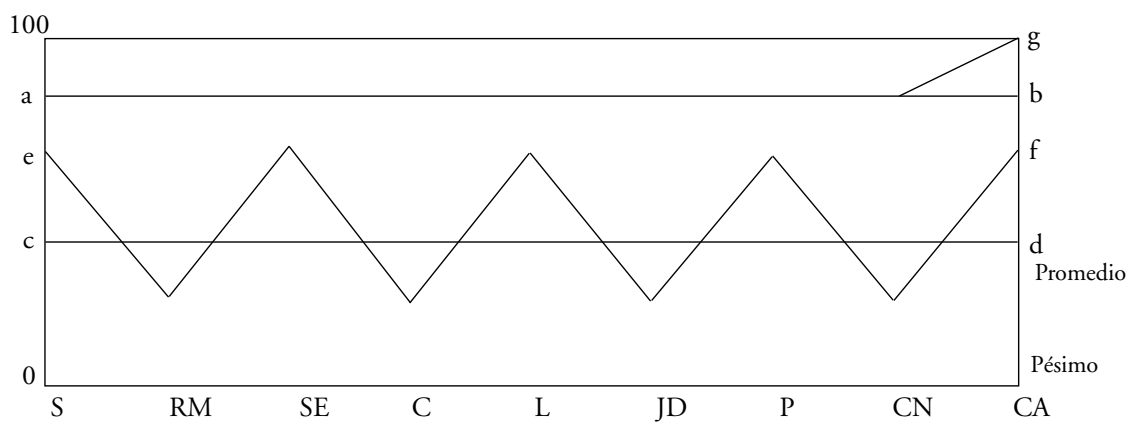

Figura 6. Tipos de perfiles axiológicos.

Es importante destacar el significado humanístico que implica esta perfilación, ya que la organización social (sus rectores en cada momento) no deberían tener otro objetivo que:

a) Elevar el promedio del perfil (línea $a-b$ en figura 6 ).

b) Allanarlo lo más posible por mor del equilibrio axiológico interno entre los valores (la línea $c$ - $d$ resultaría preferible a la $e-f$ ).

c) Tender a incrementar la diversidad y el número de los indicadores.

Si hubiera que admitir un "desequilibrio» interno entre los valores de un perfil y en virtud del humanismo fundacional de la teoría axiológica, quizás el único valor que sobresaldría por encima de los demás fuera el llamado «calidad de las actividades», el cual englobaría las dimensiones teóricas de autorrealización, participación, crítica, creatividad, expresión artística, ocio, etc. como medios de cultivo de la persona humana y de su voluntaria expresión. Si algún «pico» habría de mostrar el perfil (línea a-g en la fig. 6), sería cuando la persona prefiera potenciar dicho valor por encima de todos los demás.

\section{Subjetivación}

Las salidas $(Y)$ de los sistemas sociales son inevitablemente objetivas $Y(O)$ y subjetivas $Y(S)$. Las primeras registran hechos estadísticos contables, como «días/curso de formación impartidos», "días de trabajo perdidos por conflictos laborales», «horas extras trabajadas» o «unidades vendidas». Salidas que se pueden evaluar, bien teniendo en cuenta los niveles o estados finales de los indicadores, bien los flujos o diferencias entre los niveles inicial y final. La numerización creciente de la sociedad y la proliferación de bancos de datos facilitan la operacionalización de estas salidas objetivas. Las segundas (subjetivas) registran, por contra, las opiniones que la población de cada sistema tiene sobre el nivel alcanzado de las salidas objetivas anteriores, lo que puede 
representar una fuerte crítica a las mismas (Flood, 1995). Dado que ambos tipos de salidas estarían perfectamente cuantificadas dentro de un intervalo de variabilidad común, $0-100$, donde 0 representa el mínimo o pésimo y 100 el máximo u óptimo, una expresión integradora tomaría la forma promedio $Y=(Y(O)+Y(S)) / 2$, donde $Y(O)$ e $Y(S)$ son a su vez promedios de los niveles 0-100 alcanzados en cada uno de los valores (y éstos a su vez promedios de los indicadores que los operacionalicen) del PRV. Se sobreentiende entonces que la organización no sólo ha de hacerlo bien, sino también conseguir que su personal (y el resto de los ámbitos sociales con los que se relaciona) así lo perciba.

En este sentido, cada una de las personas de la organización no sólo serían sujetos históricos, sino también sujetos epistemológicos (Von Foerster), aunque su percepción haya de pasar por alguno de los tres niveles de subjetividad («conciencia discursiva», "conciencia práctica» e "inconsciencia») señalados por Giddens (1984). Representaría una manera de integrar en la evaluación del sistema lo que R. Vallée (1990) llama «operador observacional».

En suma, debe quedar claro que las salidas objetivas son:

$$
Y(O)=(Y(O) 1+Y(O) 2+\ldots \ldots \ldots+Y(O) 9) / 9
$$

donde «9» es el número de valores que contiene el patrón referencial (PRV)

Y las subjetivas:

$$
Y(S)=(Y(S) 1+Y(S) 2+\ldots \ldots+Y(S) 9 / 9
$$

\section{Sociologización}

La cuantificación analítica de las salidas subjetivas $Y(S)$ puede extenderse y subdividirse cuantificando por separado los «sistemas de valores» de los diferentes grupos y ámbitos sociales que conforman la organización. La operación de «sociologización» (observar el comportamiento de la organización desde el punto de vista de su personal (la "gente de la calle» si se trata de una organización política) comprendería entonces la autoevaluación de dimensiones como las necesidades $(N)$ del conjunto de individuos, divisible a su vez en diversos subconjuntos: la memoria $(M)$ o registros de las realizaciones pasadas; las necesidades específicas de las élites rectoras u órgano inspirador de la organización $(O I)$; el proyecto de sociedad que dichas élites intentan potenciar o sistema ideal de valores $(S I V)$; el sistema de valores reproyectado o propuesto como más realista por los órganos ejecutivos $\left(Y_{p}\right)$, y, finalmente, el sistema de valores realizado por el entorno más significativo $(E)$. Tanto la población en general como los diferentes colectivos deben proceder a evaluar su particular forma de percibir lo que el sistema hace en relación con cada uno de los valores e indicadores del perfil. La teoría axiológica completaría así su proceso de perfilaciones. No sólo la organización en su conjunto estaría representada por un perfil promedio $(N)$ de todos los perfiles individuales (cada persona es en este sentido, y como mínimo, una pareja de perfiles: el inicialmente deseado (Ni) 
y el percibido como realizado $Y(S) i)$, sino que cada grupo de intereses y en cada fase del proceso pasan por el registro de sus respectivos perfiles «deseados» y «percibidos». Esta superposición de perfiles dará lugar al análisis desviacional descrito en la hipótesis 15 . Se comprende entonces que toda buena gestión (política, empresarial u otra) comience con el conocimiento que proporcionan los diferentes perfiles en los que se subdivide sus diferentes ámbitos sociales.

\section{Eficiencia organizacional}

Llegados a este punto, es posible atacar el esperado concepto de EFICIENCIA ORGANIZACIONAL (performance) con algunas posibilidades de éxito. En este punto me remito a un trabajo reciente (Parra Luna, 1999), donde presenté un modelo de cálculo de los conceptos de eficacia organizacional y empresarial. En dicho trabajo sostuve las seis conclusiones siguientes:

a) Una organización social es eficiente, si, y sólo si, es EFICAZ (consigue lo previsto), lo que en términos operativos significa que la relación $Y / Y p$ debe resultar igual o mayor que la unidad y que un índice de correlación O-1 (Mills, 1962) entre los vectores $Y$ e $Y p$ debe ser igual o cercano a la unidad. Ambos coeficientes son promediables, o bien multiplicables, si se desea obtener expresiones más reducidas o alejadas de 1 .

b) Una organización social es eficiente, si, y sólo si, es ECOLÓGICA (obtiene una deseable relación insumo/consumo), lo que en términos operativos significa que la relación $T=Y / X$ debe resultar igual o mayor que la unidad.

c) Una organización social es eficiente, si, y sólo si, es EFECTIVA (es aceptada por las personas que la componen), lo que en términos operativos significa que la relación $Y(S) / N$ debe resultar igual o mayor que la unidad, y que el índice de correlación entre los vectores $Y(S)$ y $N$ resulta igualmente cercano a la unidad.

d) Una organización social es eficiente, si y sólo si, está ADAPTADA (presenta al menos iguales grados de eficacia, ecología y efectividad que el promedio de la organización de su entorno $(E)$ más significativo), lo que en términos operativos significa que la expresión $1 / 1+Y-(C E)$ oscila muy cercana a la unidad, y que el índice de correlación entre los vectores $Y$ y $(C E)$ es igual o cercano a la unidad.

e) Una organización social es eficiente, si, y sólo si, está axiológicamente EQUILIBRADA (si la variación entre los niveles alcanzados en los valores es significativamente pequeña), lo que en términos operativos significa que la desviación típica entre los valores del vector $Y$ resulta ser significativamente pequeña, o el promedio de las desviaciones típicas separadas de $Y(O)$ e $Y(S)$.

f) A la organización social empresarial se le añade un sexto requisito. Postulándose que una organización social empresarial es eficiente si, y, sólo si, es RENTABLE (alcanza unos determinados beneficios netos equivalentes a los alcanzados por su entorno económico), lo que en términos opera- 
tivos significa que la expresión $B E / B(E)$, donde $B E=$ beneficios netos alcanzados por la empresa y $B(E)=$ beneficios netos alcanzados por el promedio de las empresas del entorno resulta ser igual o mayor que la unidad.

Estos seis requisitos, al estar representados por expresiones que van a oscilar todos alrededor de la unidad, pueden ser integrados en un índice complejo que exprese la EFICIENCIA ORGANIZACIONAL (EO). Así, si llamamos a la eficacia $(E)$, al índice ecológico $(E c)$, a la efectividad $(E f)$, a la adaptación $(A)$, al equilibrio $(E q)$ y a la rentabilidad $(R)$, tenemos que la EFICIENCIA ORGANIZACIONAL EMPRESARIAL (EOE) se expresará como $E O E=(E+E c+E f+A+E q+R) / 6$, cociente que producirá un resultado cercano a la unidad. Si $E O E=1$, la organización social (en este caso la empresa) será eficiente; si $E S>1$ hipereficiente, y si $E S<1$ hipoeficiente. Fórmula final que puede representar una visión complementaria de la noción de viabilidad en Beer (1979). Las organizaciones no empresariales utilizarían la expresión $E O=(E+E c+E f+A+E q) / 5$, con idénticas propiedades que la anterior.

\section{Análisis desviacional}

Puesto que todas las expresiones del punto 13 están basadas en el mismo patrón referencial de valores (PRV), resulta perfectamente factible proceder a un análisis desviacional a través de todas las combinaciones posibles entre los nueve perfiles mencionados $(Y, Y(O), Y(S), N, M, O I, S I V, Y p$ y $(E)$ tomados de dos en dos, es decir podemos calcular: $n ! / 2 !(9-2) !=36$ desviaciones. Por ejemplo, supóngase que $N$ (el nivel de satisfacción que la población espera del sistema) se compara con lo que el sistema ha realizado objetivamente $Y(O)$ como en la figura 7 . Dicha comparación (hipotética) sugeriría los siguientes interrogantes: ¿Por qué en los valores riqueza material $(R M)$, conocimiento $(C)$, libertad $(L)$, prestigio $(P)$ y conservación de la naturaleza $(C N)$ se han sobrepasado las expectativas o deseos de la población $(N)$, mientras que en los

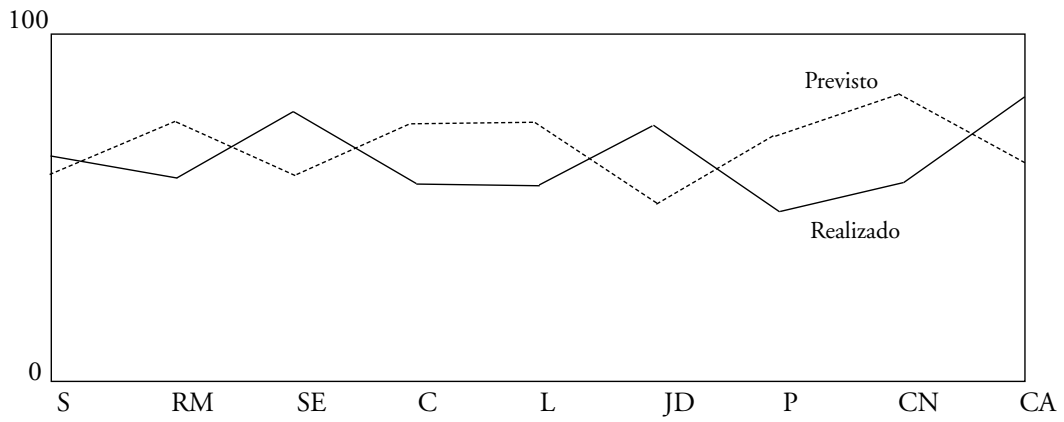

Figura 7. Análisis desviacional. 
valores seguridad ( $S e$ ), justicia distributiva (JD) y calidad de las actividades (CA) no se ha llegado? ¿Por qué tan alto grado de incumplimiento en los valores justicia distributiva $(J D)$ y calidad de las actividades $(C A)$ ?

La posibilidad de llevar a cabo las 36 comparaciones entre los perfiles sugeridos (pueden elaborarse muchos más donde pueden incluirse algún centenar de indicadores por perfil) da idea de las posibilidades analíticas de la teoría axiológica. La expresión $D i=N / Y(O)$, por limitarnos al ejemplo comentado, debe oscilar alrededor de la unidad, pudiéndose establecer que si $D i=1$ existe ajuste entre lo demandado por la población (en este caso) y lo realizado por el sistema; si $D i>1$ las expectativas de la población no han sido satisfechas y si $D<1$ lo han sido sobrepasadamente. En general, dicho análisis desviacional puede, por otra parte, cobrar una importancia singular, ya que: a) este concepto de desviación afecta a toda la población del sistema, y b) representa igualmente la totalidad del sistema de valores como objetivo global del sistema social.

\section{Cambio social}

Contemplada rutinariamente la organización desde sus ámbitos sociales o la sociedad desde la perspectiva del «hombre de la calle», puede postularse que una organización social cambia sólo cuando cambia lo que hace en beneficio de las personas que dependen de la misma o, más concretamente, cuando cambia significativamente su vector de salidas $(Y)$. Los cambios internos producidos en la estructura transformadora (por ejemplo, cuando un Estado nación cambia el número de ministerios) o en las entradas (aparición fortuita de un mineral valioso), resultarían seguramente relevantes para explicar los cambios en las salidas, pero no para describirlos, no para definir la noción de cambio «sociologizado» o desde la perspectiva de la población, no para evaluar o juzgar el comportamiento de la organización. El cambio debe afectar al sistema de necesidades de la población y, correspondientemente, al sistema de valores realizado para satisfacerlas, no meramente a los mecanismos de procedencia de estos valores. El concepto formal de CAMBIO se presenta entonces como un caso particular de la subteoría de la desviación avanzada en el punto anterior, donde las diferencias vienen ahora marcadas por dos momentos cualesquiera en el tiempo. Por ejemplo, el cambio producido entre los momentos 1 y $2 \mathrm{del}$ sistema de valores producido $C Y_{12}$ vendría expresado por:

$$
C Y_{12}=\sum\left|Y_{2}-Y_{1}\right| i
$$

donde $i=n$ representaría el numero de indicadores del PRV.

\section{Progreso/regresión social}

Los nueve valores del PRV y sus correspondientes indicadores representan todos ellos apetencias personales perseguidas y consideradas como buenas y valiosas, se supone que para la mejor autorrealización individual y colectiva 
del sistema social. Luego bien puede postularse que un incremento neto en el nivel del conjunto de dichos indicadores representaría «progreso social», si es que se respeta el PRV surgido del modelo formalmente promulgado por la ONU. Como se ha visto, la metodología empleada sitúa a todos los indicadores (objetivos y subjetivos) en el eje común positivo $0-100$, de forma tal que no es posible la aparición de números negativos. La noción de progreso $(P)$ vendrá dada entonces por la suma de todos los cambios positivos $(+)$ producidos entre dos momentos diferentes, 1 y 2 . Tenemos, pues, que:

$$
P_{12}=\sum_{i=1}^{j} d(+) i
$$

donde $j$ señala el número de entre los indicadores del PRV que han cambiado positivamente. Por contra, se calcularía igualmente la noción de regresión social $(R S)$ como:

$$
R S_{12}=\sum_{i=1}^{k} d(-)
$$

donde $k$ señala ahora los indicadores que han cambiado negativamente. Se puede calcular finalmente un índice de progreso/regresión (IPR), cuya expresión sería:

$$
I P R_{12}=P / R S
$$

donde si $I P R=1$ la sociedad habría estado durante el periodo 1-2 axiológicamente estancada; por contra, si $I P R>1$, ha existido progreso y si $I P R<1$, regresión social.

\section{Comportamiento ético}

Otro caso particular del análisis desviacional del punto 17 lo representa la definición operacional y posible cálculo del comportamiento ético de una organización. En efecto, el comportamiento ético puede definirse en principio como la desviación producida entre lo que el sistema debió y pudo hacer y lo que finalmente hizo (Beer, 1972; Van Gigch, 1978; Minati, 1998), y donde ambos términos de la diferencia pueden ser en principio aceptablemente cuantificados (Bunge, 1989). Lo que el sistema logró hacer está representado con cierta exactitud por $Y$ como índice complejo de los $n$ indicadores empíricos (objetivos y subjetivos) que comprenda en cada tipo de organización social. Sí presenta, sin embargo, un mayor problema definir lo que el sistema debió hacer y para ello sugiero elaborar un nuevo concepto: el de necesidad integral $(N I)$, el cual vendrá determinado en función de: $a$ ) las necesidades $(N)$ de la población; $b$ ) las realizaciones del entorno $(E)$, y $c$ ) la opinión de un grupo representativo de expertos $(E)$. Puesto que $N, E$ y $E$ serían perfiles axiológicos en el intervalo común 0-100, el nuevo perfil NI puede calcularse como el pro- 
medio (sin ponderar) de los tres vectores: $N I=(N+E+E) / 3$, o bien ponderado en la forma: $N I=(N a+E \mathrm{~b}+E c) / a+b+c$, donde $a, b$ y $c$ son pesos relativos diferentes. En cualquier caso, será obligatorio promediar uno a uno los niveles $(0-100)$ para cada uno de los $n$ indicadores siempre comunes a los tres perfiles. En consecuencia, una primera noción de comportamiento ético $(C E)$ puede expresarse en la forma:

$$
C E=\sum_{i=1}^{n}(Y-N I) i
$$

que es la mera suma de las diferencias entre el perfil realizado y el perfil debido. Sin embargo, dicha fórmula ha de afinarse todavía en un aspecto que puede resultar relevante. Puede suceder que haya acaecido alguna circunstancia ajena e imprevisible para los rectores del sistema, como por ejemplo un terremoto (negativo) o una significativa baja del precio de las materias primas importadas (positivo). Ambas eventualidades podrían ser aproximadamente evaluadas por un grupo representativo de expertos utilizando cualquier método de consenso, como por ejemplo el Delfos, y proporcionando un factor multiplicativo (@) más o menos próximo a la unidad. En caso de circunstancia catastrófica, @ debería ser mayor que 1 y en caso de circunstancia favorable, menor que 1. De esta manera, el comportamiento ético vendría dado por:

$$
C E=\sum_{i=1}^{n}(Y @-N I) i 100 / N I
$$

donde $C E$ está además expresado en porcentaje del estándar previsto o debido NI. Para una relación entre lo «ético» y su «cuantificación», véase por ejemplo Bai (1999).

\section{Teoría crítica}

La disponibilidad de los perfiles axiológicos presentados en el punto 15 (análisis desviacional) ofrece lógicamente unas posibilidades renovadas de cara a la formulación de una crítica fundada de las organizaciones sociales. En primer lugar, toda teoría crítica, si ha de ser auténtica (válida), debe fundamentarse en un análisis de la totalidad de las necesidades y valores en juego en el interior de cada organización. Precaución epistemológica obligada no sólo por la conocida interrelación entre los elementos, sino porque no resulta posible (admisible) la crítica de cualquier aspecto parcial de la organización si no se tiene en cuenta el resto de los aspectos más significativos (Spaul, 1995; Van Gigch, 1978). Totalidad epistemológica que podría quedar facilitada en la teoría axiológica mediante, al menos, cuatro vías: a) el número de los indicadores que operacionalicen válidamente el PRV de la tabla $1 ; b$ ) por la estandarización de los indicadores que permiten su transformación comparativa en perfiles; $c$ ) por la disponibilidad de la serie de perfiles necesarios para la realización del aná- 
lisis desviacional, y d) porque se trata de perfiles axiológicos que lo que traducen finalmente es el sistema de valores (opciones como "sistema de vida») que persiguen o realizan los distintos colectivos que componen cualquier organización social compleja. Se postula, por tanto, que resultaría difícil la adecuada formulación de una teoría crítica de la organización si no se basa en la observación sistemática de la serie de perfiles axiológicos necesarios.

$\mathrm{Si}$ antes de formular la crítica no se dispone de estos perfiles, resultaría aconsejable elaborarlos, lo cual es perfectamente posible. Consiste en tres operaciones no demasiado complicadas:

1. Diseñar una relación de los objetivos o metas (indicadores) más esenciales.

2. Solicitar información cuantificada sobre: $a$ ) nivel perseguido, y b) nivel realizado para cada uno de los indicadores.

3. Estandarizar la información bruta en números absolutos en un intervalo común (0-100), partiendo, por ejemplo, de que lo realizado en el periodo anterior en cifras absolutas equivalga al $50 \%$ del intervalo en cifras relativas. Aplicando esta regla (detallada en la hipótesis 10) para todos los indicadores, la disponibilidad de los perfiles sería inmediata.

\section{Diagnóstico organizacional}

¿Cómo podría llevarse a cabo un buen diagnóstico del estado de una organización social? Tampoco parece posible que se pueda realizar de forma adecuada si no se conocen previamente y como mínimo: a) la relación de indicadores o preocupaciones axiológicas de la organización (tablero de mandos); $b$ ) los estados de realización alcanzados en relación con los previstos, y $c$ ) idéntica comparación entre el perfil realizado $Y$ en relación con el perfil realizado por el entorno $(E)$.

La figura 7 presenta la primera comparación, mientras que la figura 8 presenta la comparación con el entorno. Ambas comparaciones resultarían altamente interesantes para un diagnóstico fundado de la organización, compati-

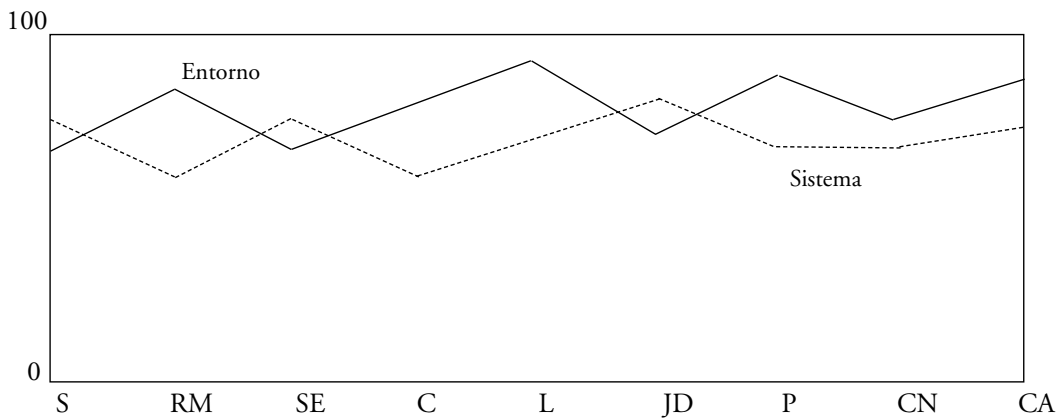

Figura 8. Realizaciones del sistema y del entorno. 
ble y complementario, por supuesto, con otros enfoques, como, por ejemplo, el neurofisiológico de Beer (1985).

\section{Análisis explicativos}

Tema de importancia capital son los análisis explicativos, demasiadas veces realizados cualitativa o intuitivamente cuando no se conoce de manera precisa el concepto de eficiencia organizacional $(E O)$. Sabemos que $E O=f(a 1, a 2, \ldots a n)$, donde $n$ puede comprender cientos de variables o factores explicativos, además interrelacionados entre sí para mayor dificultad de cálculo. No obstante, a partir de la información potenciada por el enfoque axiológico, es posible llevar a cabo explicaciones más rigurosas. La operación consistiría entonces en explicar el porcentaje de varianza que cada una de las variables $a 1, a 2, \ldots a n$, etc. aportan a la variación de $E O$ a través de metodologías adecuadas (regresión, path analysis, etc.), ya que sólo entonces se puede conocer con alguna utilidad qué variables resultan relevantes y cuáles no. Se comprende que ésta sea una operación ardua y delicada, pero puede resultar necesaria (o al menos complementaria) la estrategia de previamente inventariar, medir y clasificar la influencia real de estas variables sobre la eficiencia de la organización, que, a fin de cuentas, es lo que se persigue. La explicación axiológica propone, pues: a) definir y medir prioritariamente el concepto de eficiencia organizacional o global para tratarla como variable dependiente; y $b$ ) una vez definidas y medidas las diferentes variables que se consideren teóricamente explicativas, intentar entonces calcular el peso relativo de cada una, muchas de las cuales se encuentran entre los indicadores del propio perfil y particularmente en función de las desviaciones registradas. No debe olvidarse que la descripción de los perfiles se encontraría en la base (servirían como "materia prima») de cualquier proceso de decisión, ya que la decisión dependería del análisis explicativo (cuidadosamente ponderado dado su carácter histórico), y éste último, a su vez, del primer análisis descriptivo (la definición de $E O$ ). Formalmente se trata de una función de función, luego podría postularse que sólo la disponibilidad inicial de los perfiles es lo que permitiría análisis explicativos más exactos y completos como preludio decisional.

Resulta importante destacar que desde el momento en que $E O$ incluye en su definición operacional las salidas subjetivas $Y(O)$, se constituye en crítica autoorganizacional o reflexiva de lo que la organización hizo (pensamiento de segundo orden), lo que validaría este tipo de análisis explicativo. Por primera vez, la cibernética de segundo orden o de los sistemas observadores permite la posibilidad de un uso de la estadística, que, en vez de estar al servicio de la reproducción de lo viejo, esté al servicio de la producción de lo nuevo» (Ibáñez, 1990).

\section{Análisis cibernético}

Dado que el fin último de toda organización social es el incremento de $E O$, serían precisamente las mayores desviaciones producidas entre los perfiles de las 
figuras anteriores lo que justificaría un adecuado control cibernético de la misma. Como se sabe, el tratamiento cibernético de un sistema exige: $a$ ) fijar el objetivo a alcanzar en función de las posibilidades que permita el entorno y de otros condicionantes; $b$ ) prever cuando una posible desviación sobrepasa los límites admitidos, y c) instalar algún tipo de respuesta automática que minimice la desviación producida (Van Gigch, 1978). En un termostato, el objetivo es único: mantener el ambiente a una temperatura constante. Pero en una organización social, los objetivos son múltiples, de tal manera que el control cibernético habría de realizarse sobre todos los indicadores del perfil axiológico, así como ponderarlos y jerarquizarlos (y en comparación con el perfil del entorno), con el fin de priorizar la acción cibernética (control) allí donde las desviaciones negativas resulten más peligrosas para la viabilidad de la organización, como sucede en el campo de la empresa cuando se presentan situaciones de suspensión de pagos, pérdidas acumuladas, conflictos laborales graves o presiones determinantes del entorno político-económico, como en el caso Allende/Chile (Menanteau, 1999). El éxito de cualquier control cibernético dependerá, pues: primero, del número de indicadores del perfil; segundo, de su clasificación en función de su peso o importancia relativa; tercero, de la instrumentación preparada de antemano (por ejemplo, cibernética anticipativa), y cuarto, el coste previsto de dicha acción anticipativa. Todo control es costoso, lo que obliga además a diseñar sistemas de vigilancia automática de correcciones allí donde: a) las desviaciones son mayores; $b$ ) donde se repiten de manera mostrenca a lo largo de varios periodos, y $c$ ) donde resultan más explicativas en relación con el concepto $E G$. El control cibernético se complejiza, pues, enormemente y de ahí la escasa aplicación que se aprecia en los sociedades donde se producen demasiados subproductos negativos (desigualdad social, criminalidad, accidentes, paro, conflictos, etc.) por la ausencia, de un lado, de una cibernética anticipativa y, de otro, por la incapacidad de la cibernética retroactiva clásica para corregir las desviaciones (más policías, cárceles, hospitales, subsidios de desempleo, etc.), muchas de las cuales hasta contribuyen en ocasiones a agravar la desviación original. Desde la perspectiva de la teoría axiológica, la disponibilidad periódica de los perfiles axiológicos descritos permitiría una acción cibernética más eficaz.

\section{Diseño de sistemas de información}

Un primer examen de la lista de indicadores aplicados a la empresa (Parra Luna, 1993) puede ser una base de partida acertada para diseñar la información requerida en cualquier organización social, ya que un buen sistema de información no puede sino responder en primer lugar a la estructura de los indicadores empíricos (objetivos y subjetivos) que deban operacionalizar en cada caso el PRV. Se ha comprobado en multitud de ocasiones que, en las organizaciones burocráticas y empresariales, circulan muchas veces informaciones que apenas conservan valor o significación alguna por haber quedado obsoletas y, sin embargo, siguen existiendo por mera inercia informativa. Por contra, es muy 
posible que informaciones necesarias para calibrar o anticipar situaciones potencialmente peligrosas (mal ambiente sociolaboral, clientela descontenta, población frustrada por promesas políticas incumplidas, etc.) no circulen por el sistema con la periodicidad necesaria para el debido conocimiento de sus responsables. En definitiva, parece lógico señalar que, a partir de una lista de objetivos (indicadores), tanto rutinarios como estratégicos, debidamente consensuados por el máximo de personas en cada organización social y muy en dependencia de las exigencias de cada entorno, va a resultar notablemente más fácil llevar a cabo un adecuado diseño del sistema de información. No debe olvidarse que las organizaciones demuestran una limitada capacidad de recepcionar y manejar la información (Le Moigne, 1971), de donde se deduce la necesidad de diseños optimizados en función de dicha capacidad y de los objetivos de la organización.

\section{Procesos de decisión}

Si así sucede con los requerimientos de los sistemas de información, ¿cómo ignorar el conocimiento comparativo de los indicadores que ofrecen los perfiles axiológicos con sus "crestas» y sus "valles», sus sobrantes y sus déficits, sus desviaciones positivas y negativas... a la hora de diseñar, planificar y decidir cualquier nueva estrategia o política a seguir? ¿En qué consisten los procesos de decisión sinó en llevar a cabo las cuatro fases conocidas de criticar, diseñar, planificar y decidir sobre la base de informaciones suficientemente fiables como para tomar la decisión adecuada? En este sentido, y con independencia de otras informaciones no cuantificadas y también relevantes para la toma de la decisión, no cabe duda que la información estructurada de la serie de perfiles axiológicos apuntada en la hipótesis 15 (análisis desviacional), ofrece de partida un complemento idóneo.

\section{Optimización}

Desde la perspectiva de la teoría axiológica, y tomando como base el análisis explicativo anterior, la operación de optimizar el concepto $E O$ exigiría superar al menos dos inconvenientes:

1. Las posibles relaciones no lineales entre los fenómenos.

2. Su significación histórica mayormente irrepetible dados la complejidad interna de la organización y el dinamismo del entorno.

En principio, los perfiles axiológicos son salidas estandarizadas de las organizaciones sociales y sabemos que estas salidas reentran como nuevas entradas (condicionan el futuro funcionamiento de la organización) a través del proceso retroalimentador (feedback) propio de todo sistema social en tanto que ente transformador, de forma que no todo lo que "entra» en el sistema transformador «sale» (ineficacia o entropía sistémica), pero sí todo lo que «sale» vuelve a «entrar» de nuevo, unas veces directamente, otras a través del entorno. 
Si ello es así, la organización social se puede configurar como una compleja matriz de entradas/salidas, donde cada factor de entrada $\left(X_{1} X_{2} \ldots X m\right)$ va a explicar en grado variable cada uno de los indicadores de salida $\left(Y_{1} Y_{2} \ldots Y n\right)$. Conociendo, pues, la relación de productividad $Y i$ / Xi para cada una de las casillas de la matriz y conociendo el coste de modificar (aumentar o disminuir) la acción de los factores $X_{1} X_{2} \ldots X m$, se tendrá la oportunidad de aplicar adecuadas técnicas de optimización (Van Gigch, 1978) en busca de que la variable final $E O$ supere crecientemente (ver hipótesis 14) el valor unitario.

Ahora bien, ¿que valor definitivo tendrían dichos coeficientes? Seguramente limitado por reflejar sólo lo que sucedió históricamente. De ahí que resulte concebible algún tipo de estimación intersubjetiva pero cuantificada (por ejemplo, a través de la metodología Delfos) de estos coeficientes, para, una vez estimados, compararlos, ponderarlos y reestimarlos con los mismos coeficientes obtenidos del análisis estadístico. En resumen, la posible operación de optimización exigiría: a) una explicación estadística a partir de los datos proporcionados por la matriz de salidas $(Y)$ y entradas $(X)$; b ) una nueva estimación cuantificada por un grupo de expertos (sin conocer los resultados de la explicación estadística anterior), pero sobre el mismo número de variables, y c) reestimar y corregir los coeficientes a la vista de ambos resultados. En cualquier caso, la utilidad informativa de los perfiles axiológicos en tanto que determinan las variables a tener en cuenta, puede, pues, jugar también un papel importante en los procesos de optimización, y algunas de las críticas formuladas a la Critical System TheoryTotal Systems Intervention de Flood y Jackson (Dydley, 1995; Tsoukas, 1992 y 1993; Brocklesby, 1994; Probert, 1995) podrían perder parte de su razón de ser. Cuando una organización produce el mejor sistema de valores posible (optimizado), la crítica no parece posible. Es decir, optimización axiológica y teoría crítica serían incompatibles. Por otra parte, si, de acuerdo con Weber (en referencia a la ciencia social) y con Ulrich (1994) (en referencia a la teoría de sistemas en particular), deberían demostrar su neutralidad axiológica, parece cierto que esta operación de optimización facilitaría este objetivo.

\section{Intervención}

La llamada «intervención» en las organizaciones por parte de expertos (en particular externos) no puede dejar de basarse en una serie de informaciones que la organización les facilita. La intervención pasa entonces por tres fases: a) conocer dónde se debe intervenir; $b$ ) decidir cómo intervenir, y c) conocer cuánto cuesta intervenir. En ambas fases, los perfiles axiológicos jugarían un papel fundamental, ya que, primero y en principio, donde se debe intervenir es allí donde los «valles» de los perfiles sean más profundos o donde la diferencia entre los proyectado y lo realizado resulte más desfavorablemente amplia. Los perfiles axiológicos pueden ser, así, una guía inicial invaluable para la acción interventora. En segundo lugar, y una vez que se hayan localizado los puntos de intervención más urgentes, será preciso reexaminar de nuevo los perfiles para tratar de ver en qué medida una determinada acción interventora va a 
modificar el resto de los indicadores, al menos de los más directamente relacionados (explicaciones "estadística» $\mathrm{y}$ "estimada»). Y, en tercer y último lugar, habrá de preverse el coste de "mover» cada una de las variables o indicadores seleccionados con arreglo a los principios optimizadores, intervención viable aún en el caso de organizaciones de una extrema complejidad. De la complejidad y el caos, de la irrepetibilidad, la singularidad y el comportamiento azaroso, dicen los llamados «evangelistas» del caos, pueden nacer la estructura, el orden y la comprensión. Así pues, lo mismo que $N$ (estructura axiológica que resume - promedia - las necesidades de un colectivo de personas), surgió (hipótesis 13) de la enorme variabilidad y complejidad de las necesidades individuales, también de la disponibilidad de los numerosos perfiles axiológicos puede surgir el conocimiento necesario para efectuar intervenciones eficientes. «La nueva ciencia llamada Caos, ofrece un método para ver orden y pauta donde antes sólo se observaba el azar, la irregularidad, lo impredecible, y en suma lo caótico» (Gleick, 1998).

\section{Evaluación de la intervención}

Finalmente, se supone que toda intervención persigue una mejoría de la organización en su conjunto o en alguna de sus partes (Mansell, 1995; Flood, 1991b). Muchas veces se llevan a cabo intervenciones, forzosamente parciales, cuya "rentabilidad parcial» es posible evaluarla cuantitativa o cualitativamente. Pero si la intervención tiene un alcance mayor e implica a varios de los indicadores del PRV (en particular estratégicos, o bien a toda la estructura del sistema), entonces resultaría imprescindible utilizar la noción de eficiencia organizacional $(E O)$ para compararla antes y después de la intervención. Parece claro que toda intervención seria y responsable debería poder fundamentarse en la demostración de su eficacia, la cual se mediría en principio como $E O_{1}-E O_{2}$ o antes y después de la intervención, donde la relación $E O_{1} / E O_{2}$ debería superar, como mínimo, la unidad. El incorrecto planteamiento de muchos problemas organizacionales (los llamados ill-structured problems), que están en el origen de las llamadas metodologías «blandas» y que por propia naturaleza tenderían a dificultar la posterior evaluación de las intervenciones, puede verse sustancialmente minorado al aplicar las categorías axiológico-concretas de los perfiles y sus correspondientes niveles, obligando a un replanteamiento diferente de los problemas y a una más precisa formulación de los objetivos a conseguir (Skyttner, 1996). Y aún cuando el fin último de la intervención no resulte ser tan «reparador» como «reflexivo» (hacer comprender las causas de los problemas), el amplio análisis desviacional (hipótesis 15) facilitaría significativamente el análisis crítico de la organización.

\section{Conclusión}

El presente esbozo de teoría axiológica de la sociedad termina y empieza con la descripción de estas veintisiete hipótesis, en tanto que contempladas desde las 
cuatro «esquinas» conceptuales de un edificio teórico diseñado en principio para estar al servicio de la persona humana y su autorrealización máxima. La teoría pretendería por ello (a través de los "perfiles») dar cuenta de las necesidades y valores que subyacen en la conducta humana más universal, y, como corolario de ello, relativizar el significado profundo de las ideologías que no serían más que «sistemas de valores» diferentes (en principio ni mejores ni peores), o simples acentos o preferencias puestos sobre uno o varios valores a costa de otros. El enfoque axiológico pretendería, pues, conjugar lo ideológico con lo antiideológico. De una parte, porque se asume que cualquier formulación conceptual o teórica representa un sistema de ideas contemplable en principio como una inevitable ideología, por escondida o subrepticia que se presente. De otra, porque se asume también que sólo un permanente proceso de optimización global de las variables más relevantes de cada organización (lo que requiere simultáneamente el incremento de la variedad y el número de los indicadores de salida, su realización al máximo nivel, la reducción de su variabilidad interna, la minimización de su coste, y el cumplimiento de los estándares previstos), parece posible superar la connotación negativa que se atribuye al concepto de ideología. Finalmente, vocación de servicio hacia la autorrealización (personal y colectiva), porque el enfoque que llamé RE-PER (de la rehumanización a la perfilación) gira, desde la primera a la última hipótesis, alrededor del individuo humano en busca de su máxima multidimensionalidad en el sentido de los Marx, Mounier, Marcuse o Habermas. Otra cosa es que la teoría así formulada llegue a representar algún tipo de avance hacia una tal autorrealización personal. Ante la duda, quizás lo único realista que quepa esperar es que esta concepción «axiológica» de la sociedad pueda dar pie a ser explotada por otros con mayor provecho.

\section{Bibliografía}

AbEL, R. (1976). Man is the Measure. Nueva York: The Free Press.

ARMSON, R.; IsON, R.L. (1995). «Systems and the "Polo Mint” Metaphor». En ElLIS, K.

y otros. Critical Issues in Systems Theory and Practice. Londres: Plenum.

BAI, G. (1998). «Systemic Ethics and Systems Design», mimeo.

Bauer, R.; Biderman, A.; Gross, B. y otros (1966). Social Indicators: A First Aproximation. Cambridge, Mass: M.I.T. Press.

BEER, S. (1972). Brain of the Firm. Londres: Allen Lane.

- (1979). The Heart of the Enterprise. Great Britain: John Wiley \& Son.

- (1985). Diagnosing The System. Chichester: John Wiley \& Sons.

Best, S.; Kellner, D. (1991). Postmodern Theory: Critical Interrogations. Hong Kong:

MacMillan Press.

Boudon, R. (1971). La Crise de la Sociologie. París: Mouton.

Brocklesby, J. (1994). «Let the Jury Decide: Assessing the Cultural Feasibility of Total Systems Intervention». Syst, Pract., 7: 75-86.

Buchanan, B. (1999). "The Role of Values in Measuring Performance of Social

Systems». En PARRA LunA. The Performance of Social Systems. Nueva York: Plenum. Bunge, M. (1989). Treatise on Basic Philosophy. Dordrecht: Reidel. 
Castelis, M. (1996). La Era de la Informacion. Volumen 1, La Sociedad Red. Madrid: Alianza.

Checkland, P. (1981). Systems Thinking, Systems Practice. Chichester: John Wiley \& Sons.

Chen, T.S.; Gought, T.G. (1995). «Building a Fully Integrated Hospital Information System». En ElLIS, K. y otros. Critical Issues in Systems Theory and Practice. Londres: Plenum.

Deutsch, K.W. (1974). «Politicsand Governement», Houghton Mifflin, Boston. Dudley, P. (1995). «Surviving Seeing Medusa: A Meditation on Truth in Systems Thinking». En Ellis, K. y otros. Critical Issues in Systems Theory and Practice. Londres: Plenum.

FERnÁNDEZ Ríos, M.; SÁNCHEZ, J.C. (1997). Eficacia organizacional. Madrid: Díaz de Santos.

Flood, R.L. (1990). Liberating Systems Theory. Nueva York: Plenum.

FLOOD, R.L.; JACKSON, M. C. (1991a). Critical Systems Thinking: Directed Readings. Chichester: Wiley.

- (1991). «Creative Problem Solving». Total Systems Intervention. Chichester: Wiley. Foerster, H. (1990). «Bases epistemologicas». En IbÁÑEZ, J. «Nuevos Avances en la investigacion social». Anthropos, 22. Barcelona.

Forrester, J.W.(1971). World Dynamics. Cambridge: Wright- Allen Press.

GARMENDiA, J.A. (1990). Desarrollo de la organizacion y cultura de la empresa. Madrid: ESIC.

- (1994). Tres culturas: organizacion y recursos humanos. Madrid: ESIC.

GIDDENS, A. (1984). The Constitution of Society: Outline of the Theory of Structuration. Cambridge: Polity Press.

Gigch, J. van (1978). Applied General Systems Theory. Nueva York: Haroer \& Row, Publishers.

GleICK, J. (1998). Caos: la creación de una ciencia. Barcelona: Seix Barral.

Gouldner, A. (1971). The Comming Crisis of Western Sociology. Londres: Heinemann. HaLl, B. (1994). Values Shift. Rockport, Mass.: Twin Lights Publishers.

HaLl, M. (1999). «Systems Thinking and Human Values: Towards Understanding The Performance of Social Systems». En PARRA LunA, F. The Performance of Social Systems. Nueva York: Plenum.

HarTMAn, R.S. (1967). The Structure of Value. Carbondale, USA: Southern Illions University Press.

Heller, A. (1978). La Theorie des Besoins chez Marx. París: Union Generale d'Éditions. IBÁÑ́EZ, J. (1990). «Nuevos avances en la investigación social». Anthropos, 22.

- (1994). El regreso del sujeto. Madrid: Siglo XXI.

Kamm, R. (1995). «Information Use in the "New” Organisation». En ElLIS, K. y otros. Critical Issues in Systems Theory and Practice. Londres: Plenum.

Kluwer, J.; SCHMIDT, J. (1999). "The Geometry and Dimensions of Social Systems», mimeo.

LaCHENMEYeR, CH. (1971). The Language of Sociology. Nueva York: Columbia University Press.

LAZARSFEELD, P. (1965). «Des concepts aux indices empiriques». En Boudon, R.; LAZARSFEELD, P. Les Vocabulaires des sciences sociales. París: Mouton.

LeipZiger, D.M. (1981). Basic Needs and Development. Cambridge, Mass.: Oelgeschlager, Gunn \& Hain.

LEWIN, R. (1992). Complejidad: el caos como generador del orden. Barcelona: Tusquets. 
Maiteny, P.; ReED, B. (1998). Oscillation: a Meaning and Valuescentred Approach to the Sustainability of Human Systems. Montreal: World Congress of Sociology.

MANSELl, G. (1995). «Systems Rationality and equity in a Post-Modern World». En ElLIS, K. y otros. Critical Issues in Systems Theory and Practice. Londres: Plenum. MARTín LÓPEZ, E. (1997). La sociedad global. Madrid: MT, FUFAP.

MASLOW, A. (1970). New Knowledge in Human Values. Indiana: Gegnery/Gateway, INC. Maturana, H. (1997). La objetividad. Santiago de Chile: Dolmen.

MaYOr Zaragoza, M. (1998). Los derechos humanos en el siglo veintiuno. Barcelona: Unesco/Icaria.

Menanteau, D. "Cybernetics and Social Developement», mimeo.

Mesarovic, M.; Pestel, E. (1974). Strategie Pour Demain. París: Seuil.

Mills, F.C. (1962). Métodos estadísticos. Madrid: Aguilar.

Minati, G. (1998). Sistemica: Etica, Virtualitá, Didáctica, Economia. Milán: Apogeo.

Moigne Le, J.L. Los sistemas de decision en las organizaciones. Madrid: Tecniban.

MOrRIS, D. (1967). The Naked Ape. Londres: Jonathan Cape.

Nadler, G.; Hibino, S. (1990). Breakthrought Thinking. Rocklin, Ca.: Prima Publishing.

ONU (1948). Universal Declaration of Human Rights. Nueva York.

PARRA LUNA, F. (1982). Elementos para una teoría formal del sistema social. Madrid: UCM.

- (1993). El balance integrado de la gestión estratégica. Bilbao: Deusto.

- (1999). "Hacia la medida de la eficiencia de las organizaciones». Ponencia en Sistémica 99, Lima Perú, junio/julio 1999.

PONS RÀFols, X. (1998). La Declaracion Universal de Derechos Humanos. Barcelona: Icaria.

Probert, S.K. (1995). "The Tecnicism of Systems Thinking». En Ellis, K. y otros. Critical Issues in Systems Theory and Practice. Londres: Plenum.

Richard, N. (1993). "Sofware Quality- Can we really afford it?». En STOWELl, F. y otros. Systems Science Addresisng Gobal Issues. Nueva York: Plenum.

Rorty, R. (1979). Philosophy and the Mirror of Nature. Oxford: Blackwell.

SKYTTNER, L. (1996). General Systems Theory. Londres: Macmillan Press.

SOROKIN, P.A. (1959). "The Powers of Creatives Unselfish Love». En MasLOw, A. New Knowledge in Human Values. Indiana: Gateway.

Spaul, M. (1995). "An Ethical Basis for Critical Systems Thinking». En Ellis, K. y otros. Critical Issues in Systems Theory and Practice. Londres: Plenum.

SutTon, D. (1993). «Enterprise Design-A Total Systems Approach to Information Systems Development?». En STOWELL, F. y otros. Systems Science Addressing Global Issues. Nueva York: Plenum.

Terlekyi, N.E. (1970). «Measuring Progress Toward Social Goals. Some Possibilities at National and Local Levels». Managemenr Science, 16, n. 12, B-770.

Tsoukas, H. (1992). «Panoptic Reason and Search for Totality: A Critical Perspective of the Critical Systems Perspective». Hum. Relat, 45: 637-657.

- (1993). "The Road to Emancipacion is Trought Organisational Developement: A Critical Evaluation of Total Systems Intervention». Syst. Pract., 6: 53-70.

Turner, B.S. (1996). Social Theory. Mass.: Blackwell Companion.

Turner, B.; Hamilton, P. (1989). Critical Concepts. 2 vol. Londres: Routledge.

Ulrich, W. (1987). "Critical Heuristics of Social Systems Design». European J. of Op. Reser.,31.

VAlléE, R. (1990). «Plato’s Cave Revisited». Kybernetes, volumen 19, número 3.

Wilson, E.O. (1975). Sociobiology. Harvard, USA: Belknap. 